\title{
Wave Period and Grain Size Controls on Short-Wave Suspended Sediment Transport Under Shoaling and Breaking Waves
}

Christensen, Drude F.; Hughes, Michael G.; Aagaard, Troels

Published in:

Journal of Geophysical Research: Biogeosciences

DOI:

10.1029/2019JF005168

Publication date:

2019

Document version

Publisher's PDF, also known as Version of record

Citation for published version (APA):

Christensen, D. F., Hughes, M. G., \& Aagaard, T. (2019). Wave Period and Grain Size Controls on Short-Wave Suspended Sediment Transport Under Shoaling and Breaking Waves. Journal of Geophysical Research: Biogeosciences, 124(12), 3124-3142. https://doi.org/10.1029/2019JF005168 
JGR Earth Surface

\author{
RESEARCH ARTICLE \\ 10.1029/2019JF005168 \\ Key Points: \\ - Due to smaller phase-lag effects \\ between velocity and sediment \\ concentration, swell waves favor \\ beach recovery compared to wind \\ waves \\ - Strong undertow and infragravity \\ waves limit beach recovery by \\ reducing variations in suspended \\ sediment concentrations over a \\ wave cycle \\ - Plunging breakers were more \\ efficient than spilling breakers and \\ surf bores in suspending sediment \\ and transporting it onshore
}

Correspondence to:

D. F. Christensen,

dc@ign.ku.dk

Citation:

Christensen, D. F., Hughes, M. G., \& Aagaard, T. (2019). Wave period and grain size controls on short-wave suspended sediment transport under shoaling and breaking waves. Journal of Geophysical Research: Earth Surface, 124, 3124-3142. https://doi.org/10.1029/ 2019JF005168

Received 23 MAY 2019 Accepted 11 DEC 2019 Accepted article online 27 DEC 2019 Published online 30 DEC 2019

(C)2019. American Geophysical Union. All Rights Reserved.

\section{Wave Period and Grain Size Controls on Short-Wave Suspended Sediment Transport Under Shoaling and Breaking Waves}

\author{
Drude F. Christensen ${ }^{1}$, Michael G. Hughes ${ }^{2,3}$, and Troels Aagaard ${ }^{1}$ \\ ${ }^{1}$ Department of Geosciences and Natural Research Management, University of Copenhagen, Copenhagen, Denmark, \\ ${ }^{2}$ Science Division, NSW Office of Environment and Heritage, Sydney, New South Wales, Australia, ${ }^{3}$ School of Earth and \\ Environmental Science, University of Wollongong, North Wollongong, New South Wales, Australia
}

\begin{abstract}
Beach recovery is key to the continued existence of sandy beaches and is typically driven by the onshore-directed transport of sediment by short waves during low-moderate energy conditions. The physical processes governing beach recovery are not well understood, but the theoretically developed dimensionless fall velocity, $\Omega=H / w_{s} T$, was suggested to be important for separating onshore/offshore sediment motion (Dean, 1973). In this paper, the effect of wave period and sediment grain size on short-wave suspended sediment flux was investigated based on field measurements obtained beneath shoaling and breaking waves at Durras and Vejers beaches. The efficiency of the breaking waves in transporting suspended sediment onshore was roughly the same for the two beaches, despite the wave periods being larger and the mean sediment grain size coarser at Durras beach. The flux efficiencies were, however, shown to be degraded by wave-current interactions and long/short-wave interactions at Durras beach, especially. Excluding time series of strong undertow velocities $(<-0.1 \mathrm{~m} / \mathrm{s})$ and infragravity wave-energy $\left(>5 \mathrm{~m}^{2} / \mathrm{s}^{3}\right)$ resulted in significantly larger flux efficiencies beneath breaking waves at Durras beach compared to Vejers beach. These results indicate that wave-current interactions and long/short-wave interactions should be taken into consideration along with the wave period and mean grain size when estimating short-wave suspended sediment fluxes. The results also showed that plunging breakers were more efficient in suspending sediment and transporting it onshore compared to spilling breakers/surf bores. This finding suggests that wave breaker type also is an important parameter to incorporate when modeling beach recovery.
\end{abstract}

\section{Introduction}

Beaches are constantly gaining and losing volume through sediment transport processes. This implies that the position of the shoreline is not stationary but frequently changing, which is of interest to local residents, coastal managers, and coastal scientists (e.g., Davidson \& Turner, 2009). The rebuilding of subaerial beaches after events of sediment loss, is commonly referred to as "beach recovery" (Philips et al., 2017), and it is key to the continued existence of subaerial beaches. Beach recovery typically occurs during moderate energy conditions when incoming short-waves transport sediment onshore (e.g., Dubois, 1988; Morton et al., 1994; Osborne \& Greenwood, 1992; Shepard, 1950). Knowledge on the processes involved in beach recovery and the capability of morphodynamic models to predict shoreline progradation is, however, still limited (Kobayashi \& Jung, 2012; Philips et al., 2017; Ruessink \& Kuriyama, 2008).

Net cross-shore sediment transport depends on a variety of mechanisms, including mean currents, short waves, infragravity waves, Stokes drift, and boundary layer streaming (e.g., Aagaard et al., 2006; Henderson et al., 2004; Osborne \& Greenwood, 1992). Generally, the most important parameter contributing to onshore-directed transport is the short-wave transport, which will be examined in this paper. The short-wave (defined here as waves with periods between 2 and $20 \mathrm{~s}$ ) suspended sediment transport is a product of the coupling of fluid velocity $(u)$ and mobilized sediment load (c). Onshore-directed short-wave transport thus depends on the onshore-directed orbital velocities exceeding the offshore-directed velocities (i.e., velocity skewness) and/or more sediment being suspended beneath the wave crest than trough (i.e., suspension skewness). The magnitude and direction of the short-wave transport relies on the wave-phaserelationship between $u$ and $c$, a relationship which is affected by several surf zone processes including wave breaking, bed forms, wave-current interactions, and interactions between long and short waves 
(e.g., Aagaard et al., 2018; Bertin et al., 2018; Ruessink et al., 2011; van der Werf et al., 2007). Recent studies on breaking-induced turbulence and sediment suspension have for instance shown different $u / c$ phase-relationships for different wave breaker types. Plunging breakers tend to cause sediment suspension during the onshore wave phase due to rapid penetration of coherent vortices on or slightly ahead of the front phase of the wave (Aagaard \& Hughes, 2010; Aagaard et al., 2018; Brinkkemper, de Bakker, et al., 2017) and typically resulting in convective upward mixing of suspended sediment (Aagaard \& Jensen, 2013). Beneath spilling breakers and surf bores, diffusive mixing tends to dominate and sediment suspension often occurs on the back (front) slope of spilling breakers (surf bores; Aagaard et al., 2018; Brinkkemper, de Bakker, et al., 2017; Christensen et al., 2019). Consequently, models (such as for example energetics models: e.g., Bailard, 1981 and Gallagher et al., 1998) that rely on a simple in-phase-relationship between maximum fluid velocity and maximum suspended sediment concentration are unreliable at times when the transport is dominated by short waves (e.g., Gallagher et al., 1998; Mariño-Tapia et al., 2007; Thornton et al., 1996).

In forecasting beach profile evolution, an alternative to detailed morphodynamic/sediment transport modeling is the use of qualitative bulk-response models. These models relate environmental conditions to beach morphology based on field observations (e.g., Aubrey et al., 1980; Bruun, 1954; Yates et al., 2011). A common parameter used to describe spatial and temporal variability in beach morphology is the dimensionless fall velocity, $\Omega=H / w_{S} T$, developed by Gourlay (1968) and Dean (1973). The parameter describes conceptually how a sediment grain brought into suspension by a breaking wave (to an elevation proportional to the wave height, $H$ ) is assumed to be exposed to predominantly onshore velocities if the required time for sediment settling (depending on the settling velocity, $w_{S}$ ) is less than half the wave period ( $T$; Dean, 1973). Hence, long-wave periods and coarse sediment are expected to favor onshore-directed sediment transport because sediment suspended beneath the crest phase of the wave is likely to settle before flow reversal. Increasing wave height, short-wave periods, and fine grain sizes are, on the other hand, expected to favor offshoredirected wave-driven sediment transport. Sediment is thus expected to stay in suspension throughout the wave cycle, thereby resulting in phase-lag effects between orbital velocity and suspended sediment concentration. According to Dean (1973), a threshold of $\Omega=0.85$ separates onshore/offshore sediment motion due to waves. Temporal variations in beach morphology due to transport processes are most often related to a change in the prevailing wave conditions, as the grain size (normally) is relatively constant.

The physical processes parameterized by $\Omega$ are not fully understood (e.g., Aagaard et al., 2018; Mariño-Tapia et al., 2007; van Rijn et al., 2013). However, due to the utility of $\Omega$ in estimating the net transport direction (e.g., Miller \& Dean, 2004; Wright et al., 1985), examination of the effects of the factors directly or indirectly (undertow and wave [breaker] type) incorporated into $\Omega$ on the sediment transport is beneficial for improving sediment transport formulas. Net onshore transport of sediment (due to both waves and currents) that leads to beach recovery is promoted by (i) onshore-directed velocity skewness (typically associated with shoaling waves); (ii) more sediment suspended on the onshore wave (crest) phase than on the trough phase (suspension skewness), which may be due to a variety of processes, for example, velocity asymmetry and breaking-induced turbulence; and (iii) offshore-directed mean current velocities must be relatively weak. Relatively small waves (small $\Omega$ ) are associated with a narrow surf zone (and a relatively broad shoaling zone), and small undertow. Long-wave periods (also contributing to small $\Omega$ ) typically cause breaking waves to be of the plunging type, as shown by Galvin (1968) and Battjes (1974), which suspend sediment early on the onshore wave phase (Brinkkemper, de Bakker, et al., 2017; Aagaard et al., 2018). The penetration of breaking-induced turbulence to the bed thereby contribute to onshore-directed sediment transport, particularly when the sediment is relatively coarse-grained, as the suspended sediment is then likely to settle out of the water column before flow reversal. So the relevance of wave height and period to net sediment transport direction and beach morphology may be partly associated with undertow strength and wave breaker type, in addition to phase-lag effects. Large (small) wave heights induce strong (weak) energy dissipation and thus generation of a strong (weak) undertow (Aagaard \& Masselink, 1999), whereby suspended sediment is mainly transported offshore (onshore) by mean currents (short waves; Aagaard \& Hughes, 2013). Short-(long-) wave periods typically involve spilling (plunging) breakers and small (large) intrawave variations in $c$ with maximum concentrations behind (before) the wave crest (e.g., Aagaard \& Hughes, 2010; Aagaard et al., 2018; Brinkkemper, de Bakker, et al., 2017) resulting in small (large) short-wave suspended sediment transport rates. Thus, both wave period, grain size, breaker type, and undertow may be of 
a)
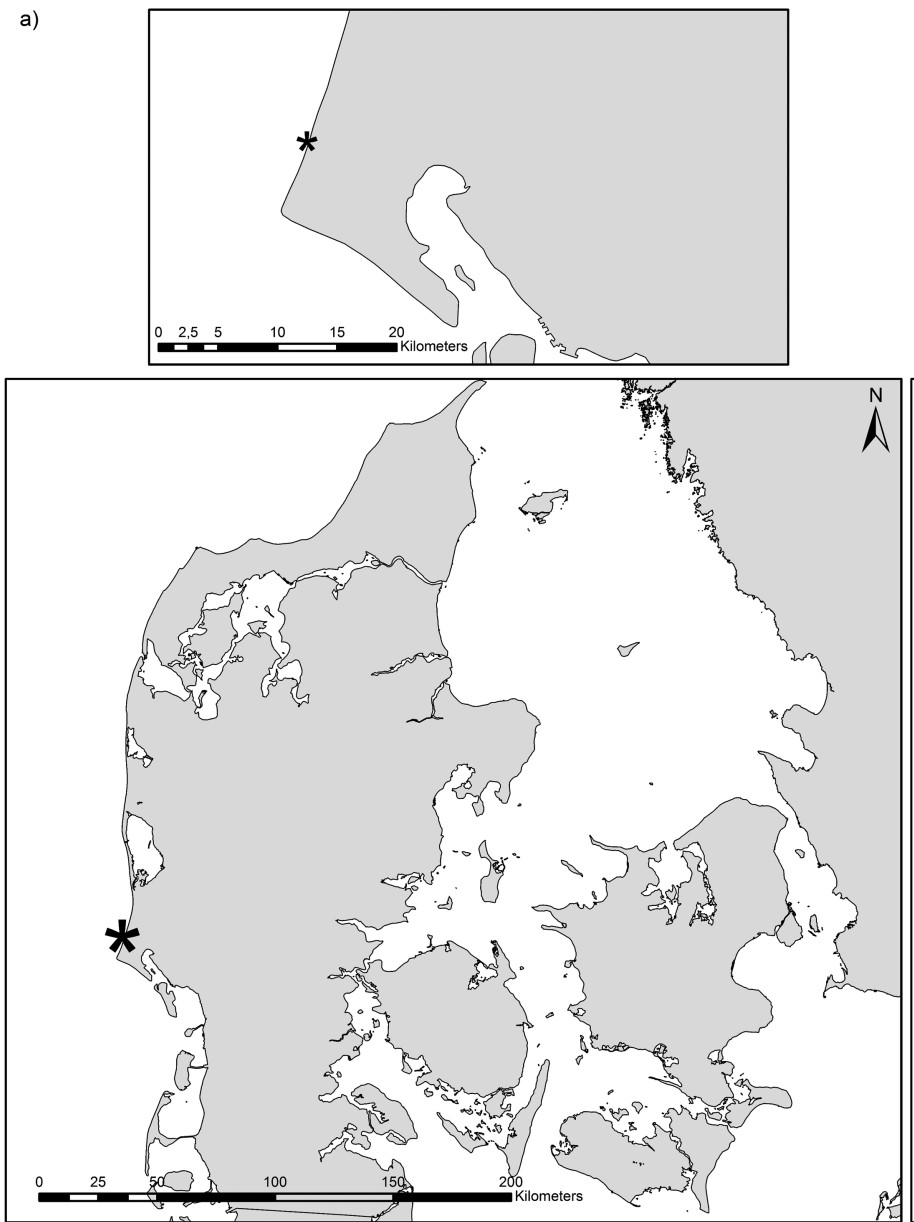

b)
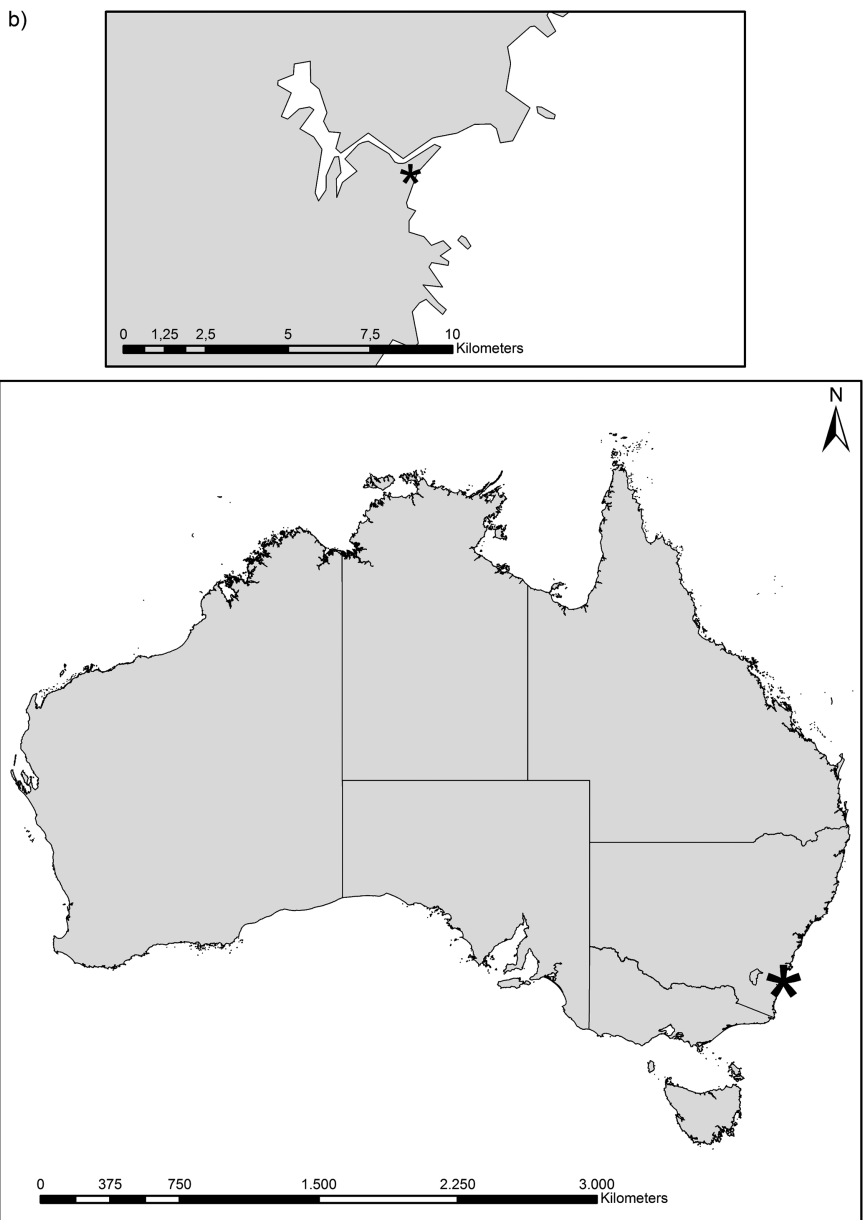

Figure 1. (a) Map of Denmark and an enlarged map of Vejers and (b) map of Australia and an enlarged map of Durras. The field sites are shown by asterisks.

importance to short-wave and net suspended sediment transport. Their relative significance is unknown but highly relevant in order to improve the understanding and modeling capability of beach recovery.

The main aim of this paper is to examine cross-shore short-wave suspended sediment flux for different sand grain sizes and for different short-wave periods representative of both wind and swell wave conditions. Based on the discussion above, we hypothesize that long-period swell waves (and coarser sediment grains, associated with larger sediment settling velocity) increase onshore-directed sediment transport as suspended sediment is more likely to settle before the wave trough phase. Moreover, we expect that the different hydrodynamic conditions across the surf zone (shoaling waves, spilling/plunging breakers, and surf bores) affect the magnitude of the short-wave suspended sediment flux. Based on studies by, for instance, Aagaard and Hughes (2010), Brinkkemper, de Bakker, et al. (2017), and Aagaard et al. (2018), we hypothesize that plunging breakers are more efficient in transporting sediment onshore than spilling breakers and surf bores due to differences in magnitude and intrawave variability of turbulence, which is important for sediment suspension. Field observations from Vejers, Denmark with dominantly wind waves and fine sand (188 $\mu \mathrm{m})$ and from Durras, NSW, Australia, with dominantly swell waves and medium sand $(360 \mu \mathrm{m})$ are used to test these hypotheses.

\section{Materials and Methods}

\subsection{Field Sites and Instrumentation}

The geographic location of the two field sites used in this study are shown in Figure 1. The TASTI (Turbulence And Sand Transport Initiative) field experiment was conducted at the beach of Vejers on the Danish North Sea coast between 17 September and 10 October 2016 (hereafter referred to as VJ16). 

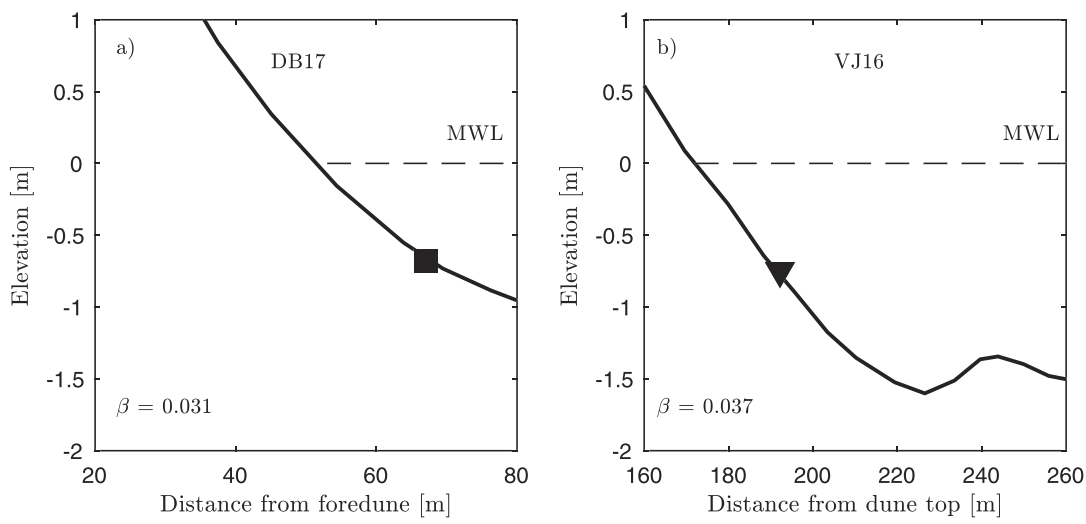

Figure 2. Cross-shore profiles at (a) Durras beach measured on 10 September 2017 and (b) Vejers beach measured on 19 September 2016. The positions of the instrument rigs are marked by the square and triangle, respectively. The mean slopes at the positions of the rigs during the field experiments were $\beta=0.031$ and $\beta=0.037$ at Durras beach and Vejers beach, respectively.

However, only data obtained until 25 September are used in this paper. The TASTI TOO field experiment was conducted at the beach of Durras in southern New South Wales, Australia, between 7 and 20 September 2017 (hereafter referred to as DB17). Data were collected in the intertidal and shallow subtidal zones where the initial, local bed slopes were $\beta_{\mathrm{DB} 17}=0.031$ and $\beta_{\mathrm{VJ} 16}=0.037$ (Figure 2). The mean sediment grain sizes at the instrument positions were $D_{\mathrm{DB} 17}=360 \mu \mathrm{m}$ and $D_{\mathrm{VJ} 16}=188 \mu \mathrm{m}$. Representative examples of the sediment grain size distributions at the two field sites are shown in Figure 3. The embayed Durras beach has a prominent rip-dominated inner bar, and during periods of larger waves, an outer bar is generated (Short, 2007). During the field experiment, the beach type (cf. Wright \& Short, 1984) was transitional between rhythmic bar and beach and transverse bar rip. The instruments were located in between two rip currents, and the bar shoal was placed about $40 \mathrm{~m}$ seaward of the instrument rig (Figure $4 \mathrm{~b}$ ). The beach at Vejers is almost straight, and several longshore bars exist on the upper shoreface (Aagaard \& Hughes, 2010). During the TASTI field experiment, a subtidal bar existed $50 \mathrm{~m}$ offshore of the instruments (Figure 2b), while an intertidal bar was located just north of the instruments (Figure 4d). The bars were generally linear. The wave climate and tidal ranges for the two beaches are given in Table 1.

During the two experiments, measurements of the velocity field, near-bed pressure, suspended sediment concentrations, and seabed morphology were collected by instruments mounted on instrument rigs consisting of a frame carrying data loggers and batteries and a triangular frame pointing seaward where the instruments were mounted (Figures $4 \mathrm{a}$ and $4 \mathrm{c}$ ). The instruments recorded data for 30 min every hour (i.e., a time series equals $30 \mathrm{~min}$ of data) to an external data logger, except for a Pulse-Coherent Acoustic Doppler Profiler (PC-ADP), which logged internally for 17 min every hour. Data from the PC-ADP were only used to detect bed level changes in this paper.

The velocity field was measured at three different elevations above the bed (Table 2) by two Sontek $5 \mathrm{MHz}$ ADVOcean sensors and one 3-D sideways-looking Sontek $10 \mathrm{MHz}$ acoustic Doppler velocimeter (ADV). The ADVs recorded at $10 \mathrm{~Hz}$ and were oriented to record positive flows onshore and upward and to the north (Vejers) and south (Durras). A vertical stack of optical backscatter sensors (OBS-3+s and UFOBS-7s, both from D\&A Instruments) measured the suspended sediment concentration in the lower $0.40 \mathrm{~m}$ of the water column (Table 2). All the (F)OBSs were logging at $10 \mathrm{~Hz}$, except for the upper OBS, which logged at $2 \mathrm{~Hz}$. Data from this OBS are not used in the paper. An Imagenex 881A Profiling Sonar made continuous crossshore scans of the seabed, while rotational scans with a diameter of $5 \mathrm{~m}$ were obtained every $20 \mathrm{~min}$ by an Imagenex 881A Imaging Sonar. The elevation of the sensors was tracked by the profiling sonar, and, if necessary, adjusted once a day during low tide. Additional information on the TASTI field experiment (VJ16) can be found in Brinkkemper, Christensen, et al. (2017) and Christensen et al. (2018).

\subsection{Data Processing}

Wave breaking in the surf zone causes the flows to become turbulent and aerated, which affects measurements from acoustic velocity sensors. The velocity records were therefore quality controlled and despiked 


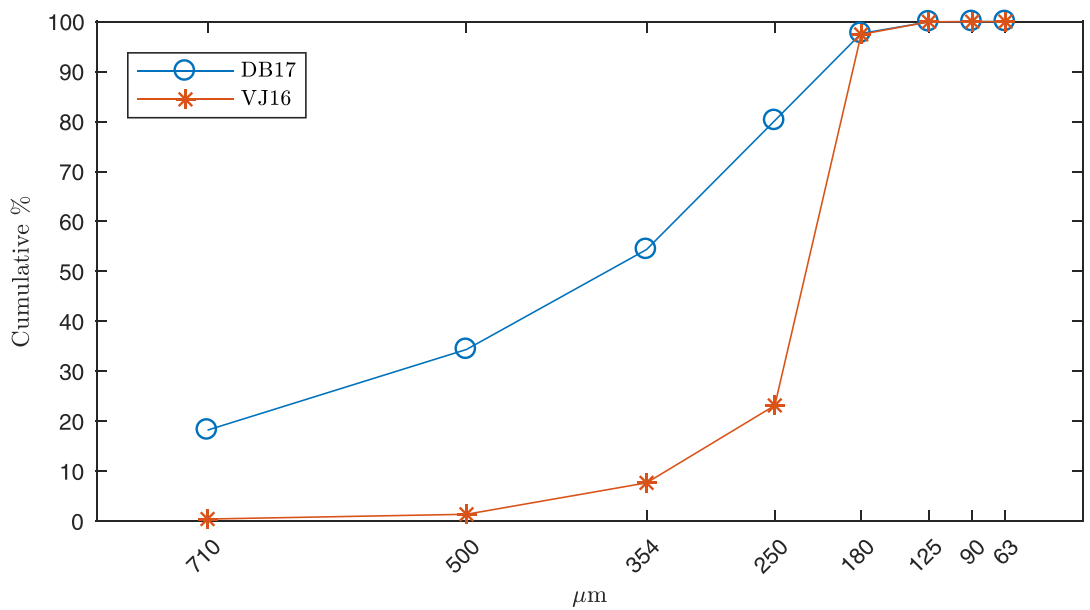

Figure 3. Sediment grain size distribution on 13 September 2017 at Durras beach (blue circles) and on 22 September 2016 at Vejers beach (orange asterisks)

in order to remove noise. The quality control followed the guidelines suggested by Elgar et al. (2005), using a signal-to-noise ratio of 20 and a signal correlation threshold given by

$$
0.3+0.4 \sqrt{\frac{s f}{25}}
$$

where $s f$ is the sampling frequency. Record spikes were identified and replaced with filtered values (using a 1-s low-pass box filter). Under strongly turbulent flows, the phase-space method developed by Mori et al.
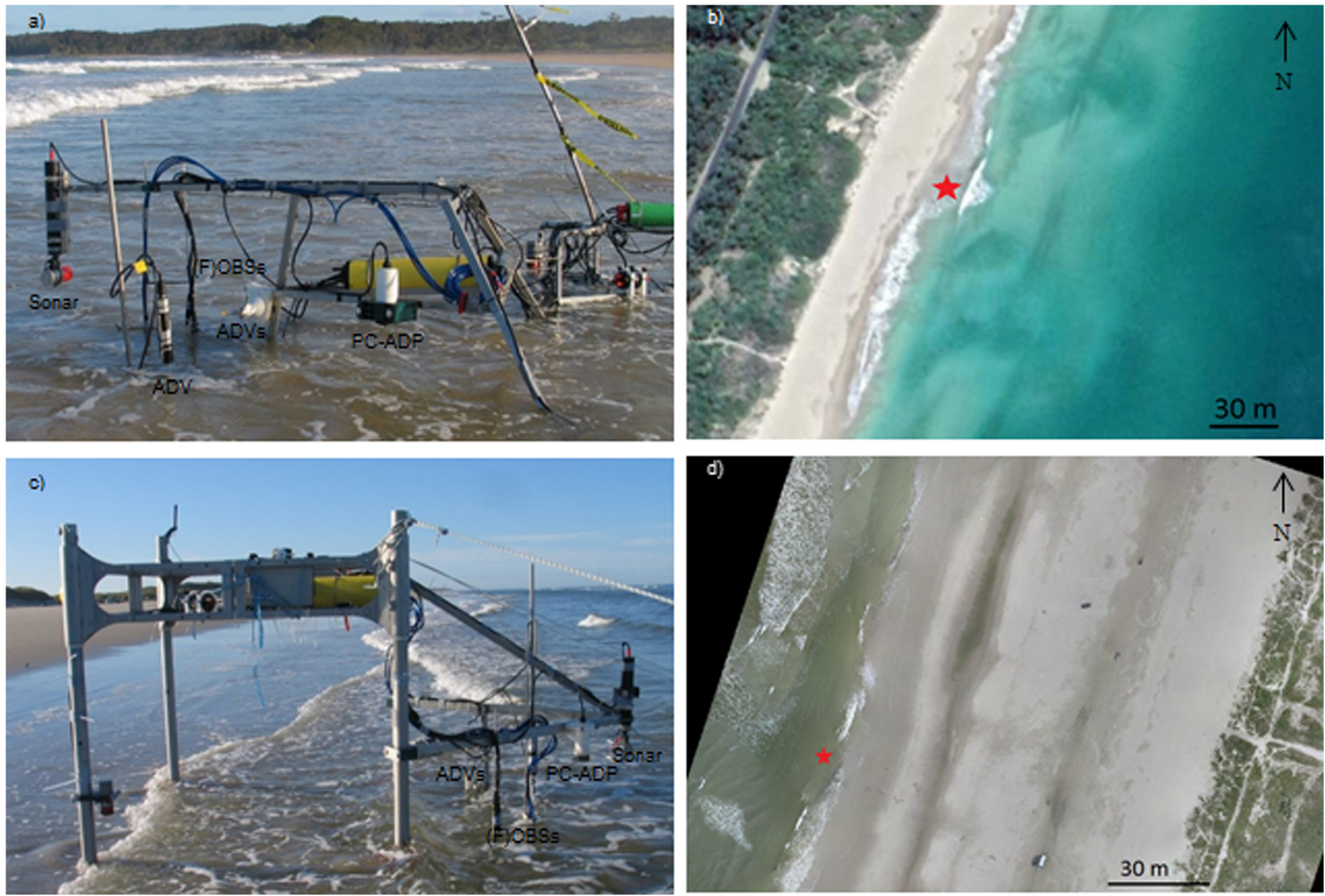

Figure 4. Photos of the instrument rigs during low tide at (a) Durras beach and (c) Vejers beach, and aerial photos of (b) Durras beach (Google Earth) and (d) Vejers beach (drone) during low tide. The positions of the instrument rigs are marked by red stars. 
Table 1

Mean Annual, Offshore Significant Wave Height $\left(H_{S}\right)$, Zero Crossing Wave Period $\left(T_{Z}\right)$, and Tidal Ranges

\begin{tabular}{lll}
\hline Wave conditions & DB17 & VJ16 \\
\hline Mean annual $H_{S}(\mathrm{~m})$ & 1.5 (Lord \& Kulmar, 2000) & 1.3 (Aagaard \& Hughes, 2010) \\
Mean annual $T_{z}(\mathrm{~s})$ & 9.4 (Lord \& Kulmar, 2000) & 4.3 (Aagaard et al., 2010) \\
Spring and neap tidal ranges $(\mathrm{m})$ & 1.7 and 1.2 (Chappell \& Eliot, 1979) & 1.2 and 0.6 (Aagaard \& Hughes, 2010) \\
\hline
\end{tabular}

Note. The offshore wave conditions were obtained from wave buoys at Batemans Bay (about $15 \mathrm{~km}$ south of Durras beach) and Nymindegab (about $20 \mathrm{~km}$ north of Vejers beach).

(2007) appeared robust, while under more moderate breaking conditions, the method appeared to be too restrictive. Spikes in the velocity records collected at Durras beach were therefore identified by use of the phase-space method following Ruessink (2010), while a spike-threshold method was applied to the data from Vejers beach (Christensen et al., 2019). In addition, for both data sets (VJ16 and DB17), the vertical velocities were further corrected as they are strongly sensitive to vertical alignment errors of the velocity sensors. To avoid horizontal velocities being biased into the vertical components, the velocity data were rotated onto their principal axes following the procedure outlined in Emery and Thomson (2001):

$$
\begin{gathered}
\alpha_{x}=\sqrt{\tan \left(\frac{2\left(u_{d s} w_{d s}\right)}{\left(u_{d s}^{2}-w_{d s}^{2}\right)}\right)} \\
w=w_{d s} \cos \left(\alpha_{x}\right)-u_{d s} \sin \left(\alpha_{x}\right)
\end{gathered}
$$

where the subscript $d s$ represents despiked velocitites, $\alpha_{x}$ is the cross-shore vertical tilt, and $w$ is the rotated, corrected vertical velocities. To correct for tilt in the alongshore dimension, $u_{d s}$ is replaced with $v_{d s}$.

Based on the processed velocity data, turbulent velocities $\left(u^{\prime}, v^{\prime}\right.$, and $\left.w^{\prime}\right)$ were estimated by frequency filtering (e.g., Foster, Beach, et al., 2006; Mocke, 2001; Scott et al., 2005), where the cutoff frequency separating wave and turbulent motions was defined based on the cross-spectral phase of $u$ and $w$ (Christensen et al., 2018). Record averages of Froude-scaled turbulent kinetic energy $(k)$ were calculated as

$$
k=\sqrt{\left(0.5\left(\overline{u^{\prime 2}}+\overline{v^{\prime 2}}+\overline{w^{\prime 2}}\right)\right) /(g h)}
$$

where $h$ is the record-averaged water depth, $g$ is the acceleration of gravity, and overbars denote a 30-min time average. Further details on the processing of the velocity data are described in Christensen et al. (2018).

The (F)OBSs were postcalibrated in a large recirculation tank using sediment samples from the field sites. Calibration curves for the on-site sand grain reflectance were constructed for each sensor, and for all records, field offsets due to background turbidity were subtracted. The offsets were estimated to correspond to the second percentile of the backscatter signals. After the calibration, the (F)OBS records were screened and visually quality controlled in order to reject signals indicating the presence of air bubbles and/or the sensor being close to (i.e., interfering with the flow) or in the bed. In the screening procedure, time series were rejected if the average suspended sediment concentrations increased with distance above the bed. In addition, if $>2 \%$ of the (F)OBS signals were saturated (using a threshold corresponding to $99 \%$ of the maximum (F)OBS signal), the time series were also rejected. In the visual control, time series were rejected when (a) concentration offsets changed markedly during the time series (due to bed level changes), (b) periods of high concentrations were not reflected

Table 2

Initial Instrument Elevations at Durras (DB17) and Vejers (VJ16) Beaches

\begin{tabular}{lll}
\hline Instruments & DB17 & VJ16 \\
\hline ADV3/2/1 & $0.50 / 0.20 / 0.05 \mathrm{~m}$ & $0.50 / 0.20 / 0.10 \mathrm{~m}$ \\
OBSs & $0.40 / 0.30 / 0.20 / 0.10 / 0.05 \mathrm{~m}$ & $0.20 / 0.10 / 0.05 \mathrm{~m}$ \\
FOBSs & $0.04 / 0.03 / 0.02 \mathrm{~m}$ & $0.04 / 0.03 / 0.02 \mathrm{~m}$ \\
\hline
\end{tabular}
in the time series recorded at the sensor below/above, and (c) the concentration levels were high (e.g., > $100 \mathrm{~g} / \mathrm{l}$ ) indicating that the (F)OBS was located just above the bed and thereby potentially interfering with the flow. The quality control of the (F)OBSs reduced the number of available time series from 288 to 236 at Durras beach and from 191 to 177 at Vejers beach. For the analyses of the short-wave suspended sediment fluxes, the most near-bed quality-controlled (F)OBS was used. Instrument elevations 
were estimated from manual measurements at daily low tide and subsequent bed level changes determined from the profiling sonar. For records without sonar data due to sensor emergence around low tide, the bed level was linearly interpolated. The most near-bed quality-controlled (F)OBS was often a sensor located just above a sensor, which was rejected due to instrument burial or flow interference. By using this approach uncertainties in the estimated instrument elevations between low tides did not affect the data selection. The maximum elevation of the selected (F)OBSs was $z<0.10 \mathrm{~m}$ corresponding to the maximum distance between adjacent (F)OBSs (Table 2).

\subsection{Analysis Techniques}

Due to wave irregularity in the field, a wave-by-wave technique where the individual waves in each time series were grouped according to their individual relative wave height was used for the analyses. The individual waves of the time series were identified from the ADV3-records, using a zero down-crossing analysis. The velocity records were high-pass and low-pass filtered in order to remove the mean, long-term trends, infragravity waves, and high-frequency noise before the limits of the individual waves were identified. The relative wave height of each wave $\left(H_{z} / h_{z}\right)$ was subsequently determined from the zero crossing wave height $\left(H_{z}\right)$ and the mean surface elevation between the zero crossings $\left(h_{z}\right)$. Surface elevations were determined by calibration of the pressure measurements taking into account the sea water salinity and temperature, and subtraction of the atmospheric pressure, which was measured when the sensor was emerged at low tide. The waves were grouped into a number of bins of equal width $\left(d\left(H_{z} / h_{z}\right)=0.1\right)$, and for each wave within the bin $u, c, k$, and the short-wave suspended sediment flux $\left(q_{s, h f}\right)$ were extracted and wave-averaged. In addition, the zero crossing wave periods $\left(T_{Z}\right)$ were determined, $k_{\max }$ within the wave cycles were identified, and the velocity skewness and asymmetry of the waves calculated $\left(S K_{u}=\overline{u_{h f}^{3}} /{\overline{u_{h f}^{2}}}^{3 / 2}\right.$ and $A S_{u}=\overline{\mathscr{H}\left(u_{h f}^{3}\right)} /$ ${\overline{u_{h f}^{2}}}^{3 / 2}$ where $\mathcal{H}$ is the Hilbert transform). Finally, the average values for each $H_{z} / h_{z}$-bin and time series were calculated for cases where the $H_{z} / h_{z}$-bin contained more than 10 waves (e.g., $q_{s, h f \frac{H_{z}}{h_{z}}, t s}$, where $H_{z} / h_{z}$ denotes that averaging is only conducted for waves within a specific relative wave height bin, and ts denotes that the averaging is only conducted for waves from a single time series). In addition, the averages across all time series were calculated (e.g., $q_{s, h f_{H_{z}} / h_{z}}$ ). If less than 20 waves contributed to the average, the specific $H_{z} / h_{z}$-bin was not included in the results.

The instantaneous $q_{s, h f}$ was estimated at a discrete sensor elevation as the product of the short-wave crossshore velocity $\left(u_{h f}\right)$ and the suspended sediment concentration $(c)$ :

$$
q_{s, h f}(t)=u_{h f} c
$$

The subscript $h f$ denotes that the data have been bandpass filtered into the short-wave components using frequency thresholds of 0.05 and $1 \mathrm{~Hz}$, respectively. The short-wave cross-shore velocities were obtained from ADV3. This sensor was selected in order to avoid velocity phase-shifts affecting the fluxes, as ADV1 was assumed to frequently be located within the wave boundary layer at Vejers beach as opposed to the OBSs, which were typically used since the FOBSs were often buried in the sand. In order to maintain consistency, ADV3 was then used at both field sites. The relatively large vertical separation distance between the ADV3s and (F)OBSs might result in underestimations of the absolute fluxes, but our focus is primarily on the relative magnitudes between different wave conditions. The wave-averaged, short-wave suspended sediment flux was scaled with the wave-averaged suspended sediment concentration (i.e., $q_{s, h f} / C_{H_{z} / h_{z}}$ ) in order to normalize variability in $q_{s, h f}$ caused by differences in $C$ between different time series. This can be caused by, for example, differences in sensor elevation and boundary layer characteristics. The term is interpreted as a normalized sediment transport, or a "flux efficiency," and allows for an examination of the influence of wave period on the efficiency by which the waves transport suspended sediment. For a more detailed description of the flux efficiency term, see Christensen et al. (2019).

To describe the hydrodynamic and seabed conditions during the field experiments, averages of 30-min time series were also applied. Significant wave height $\left(H_{s}=4 \sigma_{\eta}\right.$ in which $\sigma_{\eta}$ is the standard deviation of the water surface elevation $[\eta])$, significant wave period $\left(T_{S}=\left(m_{0} / m_{2}\right)^{1 / 2}\right.$ in which $m$ is the zeroth and second moments of the wave spectrum), mean currents $\left(U=\sum u / n\right.$, where $n$ is the number of observations), cross-shore 

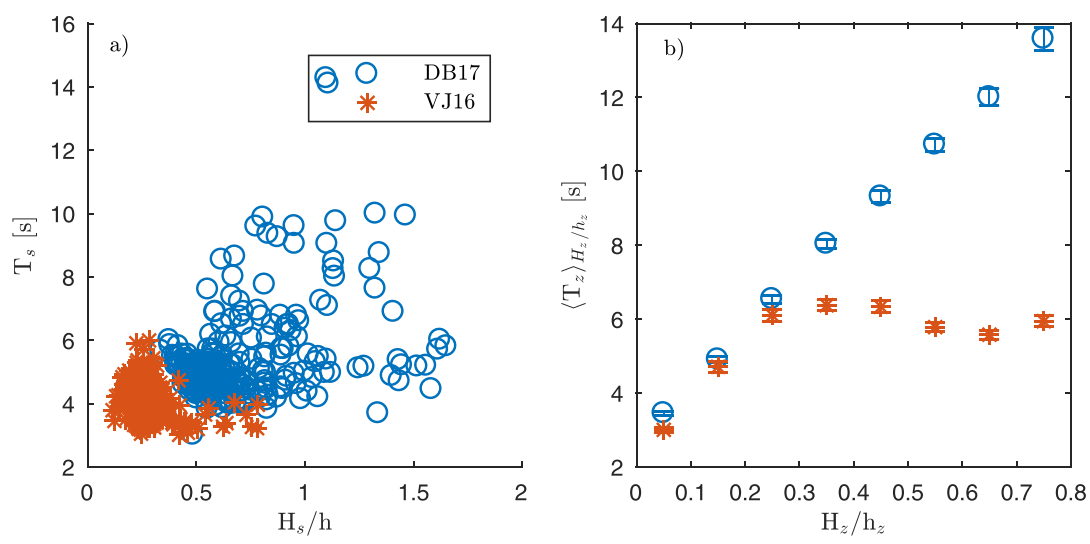

Figure 5. (a) Significant wave period $\left(T_{S}\right)$ versus relative wave height $\left(H_{S} / h\right)$ for 30-min time series and (b) zero crossing wave period $\left(T_{z_{H_{z}} / h_{z}}\right)$ versus relative wave height $\left(H_{z} / h_{z}\right)$ for grouped single waves. The error bars show the standard error on the means. Data from Durras beach are represented by blue circles and data from Vejers beach by orange asterisks.

velocity skewness and asymmetry ( $S K_{u a l l, t s}$ and $A S_{u \text { all,ts }}$ where all,ts denotes that the averaging is performed for all waves within one time series), and dimensionless fall velocity $\left(\Omega=H_{s} /\left(w_{s} T_{s}\right)\right.$, where $w_{s}$ is calculated from Soulsby, 1997) were calculated. Angle brackets with the subscript all will be used to denote the average values for the entire field experiments (e.g., $U_{\text {all }}$ ). The bed state was described by the wave ripple geometry. Based on the bed profile scans, the ripple heights were determined by $\eta_{r}=2 \sqrt{2} \sigma_{r}$, where $\sigma_{r}$ is the standard deviation of the bed elevation (Hay, 2011). To identify the ripple wavelengths $(\lambda)$, the peak in the autocorrelation function of the individual bed profiles was used.

\section{Results}

\subsection{Experimental Conditions}

Swell and wind waves dominated the wave fields during the field experiments at Durras and Vejers beaches, respectively. At Durras beach, $T_{S}=3-10 \mathrm{~s}$, while at Vejers beach $T_{s}=3-6 \mathrm{~s}$ (Figure $5 \mathrm{a}$ ). Also, for breaking waves of similar $H_{z} / h_{z}(>0.3)$, the wave period differed at the two beaches (Figure $5 \mathrm{~b}$ ), with significantly larger $T_{z H_{z} / h_{z}}$ at Durras beach $\left(T_{z H_{z} / h_{z}}=7-14 \mathrm{~s}\right)$ compared to Vejers beach $\left(T_{z H_{z} / h_{z}} \approx 6 \mathrm{~s}\right)$. Moreover, infragravity waves with wave periods about $50 \mathrm{~s}$ were dominant at times at Durras beach, especially on 10 and 11 September (Figure 6). The wide range in $H_{S}$ (Figure 7a) along with the variability in water depth due to the semidiurnal tide resulted in a range of hydrodynamic conditions at the locations of the instrument rigs with relative wave heights in the range $H_{s} / h=0.3-1.6$ and $H_{s} / h=0.1-0.8$ at Durras and Vejers beaches, respectively (Figure 7b). The larger $H_{s} / h$ at Durras beach likely resulted in a higher percentage of breaking waves (Splinter et al., 2011$)$ and consequently stronger undertow $\left(U_{\mathrm{ADV} \text { 3all; }}\right.$ Table 3$)$. Visual observations indicated that when waves were breaking, they were either the spilling or the plunging type at Durras beach, while spilling breakers prevailed at Vejers beach. The wave nonlinearity was comparable at the two field sites with respect to velocity skewness, $S K_{u, \mathrm{ADV} 3 a l l, t \mathrm{ts}} \approx 0-1$ (Table 3 ). The wave asymmetry $\left(A S_{u, \mathrm{ADV} 3 a l l, t \mathrm{t}}\right.$, Table 3), on the other hand, was more negative at Durras beach, implying that the waves were more forward pitched. In accordance with field observations (section 2.1), $\Omega$ indicates that the beaches were of intermediate states $(1<\Omega<6$; Table 3$)$ following the classification scheme by Wright and Short (1984). The value of $\Omega$ was generally larger at Vejers beach due to shorter wave periods and finer sand.

Turbulent kinetic energy levels in the water column at the two field sites showed an increase in $k_{\text {all,ts }}$ with $H_{s} /$ $h$ (Figure 8). There was no difference in $k_{\text {all,ts }}$ for similar $H_{s} / h$ at the two beaches, but overall $k_{\text {all }}$ was larger at Durras beach (Table 3) since relative wave heights were generally larger. The vertical structure of the turbulence can be examined based on class-averages of $k_{\text {all,ts }}$ for different ranges of $H_{s} / h$ (Figure 9). For waves with $H_{S} / h<0.5$ no significant vertical variations in $k_{H_{s} / h}$ appears at either Vejers beach nor Durras beach and the shape/magnitude of the mean vertical turbulence profiles was virtually similar for the two beaches. Comparable turbulence intensities at the elevations of ADV2 and ADV1, or a slight increase in $k_{H_{s} / h}$ 

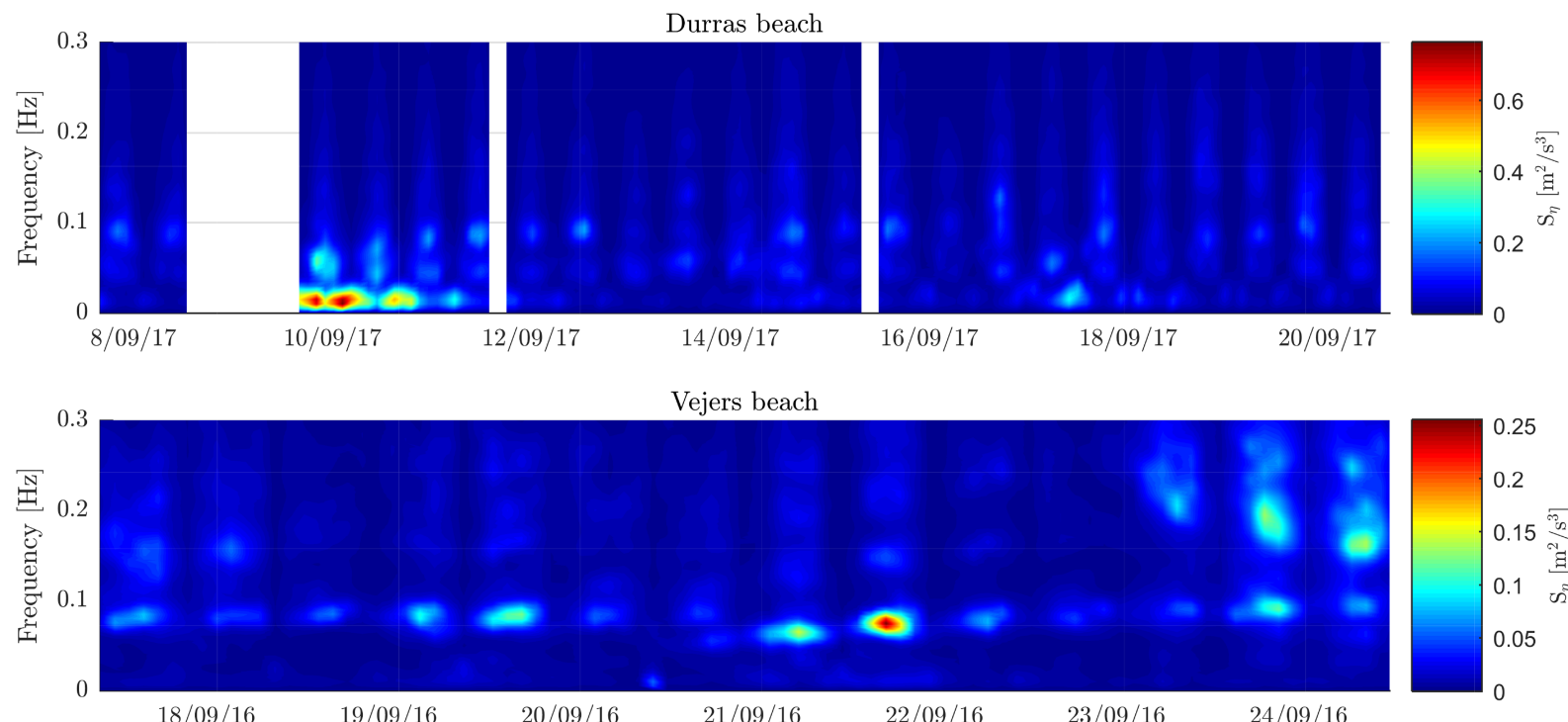

Figure 6. Wave-energy spectra at Durras beach (upper) and Vejers beach (lower).

toward the bed, suggest a turbulence contribution from bed friction. Turbulence injected at the surface thus decreases in intensity as it penetrates toward the bed. Hence, for $k_{\mathrm{ADV} 1 H_{s} / h}$ to correspond to $k_{\mathrm{ADV} 2 H_{s} / h}$ in magnitude, another source of turbulence must contribute to increase $k_{H_{s} / h}$ near the bed (ADV1). For waves with $H_{S} / h>0.5$, turbulence intensities were significantly higher in the upper part of the water column (ADV3) with $k_{H_{s} / h}$ decreasing toward the bed suggesting dominance of surface-generated turbulence.

Sonar scans of the seabed during the two field campaigns indicate the continuous presence of small-scale wave ripples (Figure 10a; $\eta_{r}=0.01-0.11$ ). Especially at Vejers beach, the ripples were occasionally of large steepness (Figure 10b, $\eta_{r} / \lambda>0.12$ ), indicating temporally larger form roughness compared to Durras beach.

\subsection{Wave Type Classification}

In order to examine $c$ and $q_{s, h f}$ associated with different wave (breaker) types, synchronized video and pressure records were used to identify the wave types occurring during nine instrument runs at Durras beach. Each wave in the time series was classified into one of five categories as it passed the location of the pressure sensor: nonbreaking waves (a total of 565 waves identified), plunging breakers (182 cases), spilling breakers
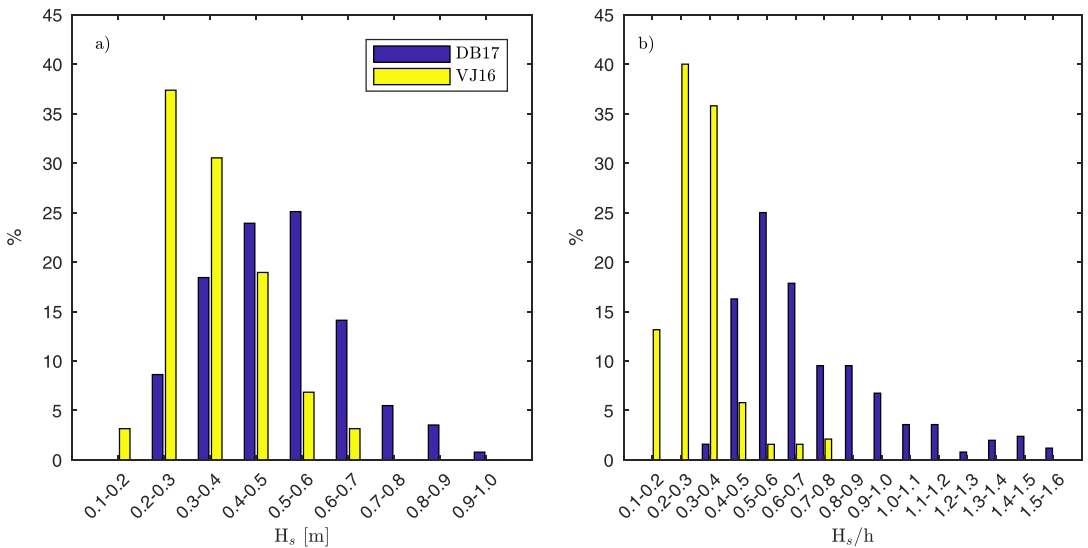

Figure 7. Histograms showing the distribution of (a) significant wave heights $\left(H_{S}\right)$ and (b) relative wave height $\left(H_{S} / h\right)$ during the field experiments at Durras beach (blue) and Vejers beach (yellow). 
Table 3

The Average, Min and Max Values of the Mean Cross-Shore Current Velocity ( $\left.U_{A D V 3}\right)$, Cross-Shore Velocity Skewness (SK $\left.\mathrm{U}_{u, A D V 3}\right)$, Cross-Shore Velocity Asymmetry $\left(A S_{u, A D V 3}\right)$, and Dimensionless Fall Velocity $(\Omega)$, and Also the Average Froude-Scaled Turbulent Kinetic Energy $\left(k_{A D V 3}\right)$ During the Field Experiments at Durras (DB17) and Vejers (VJ16) Beaches

\begin{tabular}{|c|c|c|c|c|c|c|c|c|c|}
\hline Sites & $U_{\text {ADV3all }}(\mathrm{m} / \mathrm{s})$ & $\begin{array}{l}\text { Min and max } \\
U_{\mathrm{ADV} 3}(\mathrm{~m} / \mathrm{s})\end{array}$ & $S K_{u, \mathrm{ADV} 3 a l l}$ & $\begin{array}{l}\text { Min and max } \\
S K_{u, \mathrm{ADV} 3 a l l, t s}\end{array}$ & $A S_{u, \mathrm{ADV} 3 \text { all }}$ & $\begin{array}{l}\text { Min and max } \\
A S_{u, \mathrm{ADV} 3 a l l, t s}\end{array}$ & $\Omega_{\text {all }}$ & $\begin{array}{l}\text { Min and max } \\
\Omega_{\text {all,ts }}\end{array}$ & $k_{\mathrm{ADV} 3 a l l}$ \\
\hline DB17 & -0.14 & -0.39 to -0.03 & 0.46 & $-0.08-0.90$ & -0.56 & -0.80 to -0.21 & 2.1 & $0.3-3.7$ & 0.014 \\
\hline VJ16 & -0.06 & $-0.19-0.01$ & 0.56 & $0.05-1.07$ & -0.13 & $-0.60-0.37$ & 3.9 & $2.1-7.7$ & 0.012 \\
\hline
\end{tabular}

(167 cases), surf bores (311 cases), and nonclassified (1158 cases), for a total of 2,383 waves counted and identified. Surf bores were distinguished from breaking waves by having foam covering the entire front face of the wave and by propagating onshore with a constant form. Using the pressure records, a number of parameters were calculated for each wave, including $H_{z} / h_{z}$, wave skewness $\left(S K_{\eta}\right)$ and asymmetry $\left(A S_{\eta}\right)$, the Ursell number $\left(U r=H_{z} L^{2} / h_{z}{ }^{3}\right.$ where $\left.L=T_{z} \sqrt{g h_{z}}\right)$, and the Iribarren number $\left(\xi=\tan \beta / \sqrt{H / L_{0}}\right.$ where $\tan \beta$ is the bed slope and $\left.L_{0}=(\mathrm{g} / 2 \pi) T^{2}\right)$.

An analysis of variance was performed on the parameters, where the ratios of between group variability (i.e., variation in parameter value between wave types) and the within group variability were calculated. The results showed that the best single parameter to separate the different types was the relative wave height. The group means of nonbreaking waves, plunging and spilling breakers, and surf bores were significantly different at a significance level of $\alpha=0.05$. The quartile plots (Figure 11) demonstrate, however, that not each wave can be uniquely defined and some overlap in parameter space exists. In particular, spilling breakers and surf bores exhibit a large overlap in the interquartile ranges and these two wave types are difficult to separate on the basis of $H_{z} / h_{z}$. One of the reasons for this difficulty is that these two wave types are nontrivial to separate visually since the change between them is gradual and spanning the transition between the outer and the inner surf zones. Additionally, a fairly large number of outliers in the nonbreaking group are due to waves very nearly, but not quite, breaking during their passage passed the sensor. Based on this analysis, waves with $H_{z} / h_{z}<0.3$ are henceforth classified as mainly nonbreaking, for $0.3<H_{z} / h_{z}<0.5$, waves are classified as mainly spilling breakers or bores, while for $H_{z} / h_{z}>0.5$, waves are considered to be plunging breakers. Using these limits on all individual waves during all instrument runs from Durras (Vejers) beach resulted in a total of $20 \%$ (65\%) nonbreaking waves, $48 \%$ (33\%) spilling breakers/surf bores, and $32 \%$ (2\%) plunging breakers at the instrument

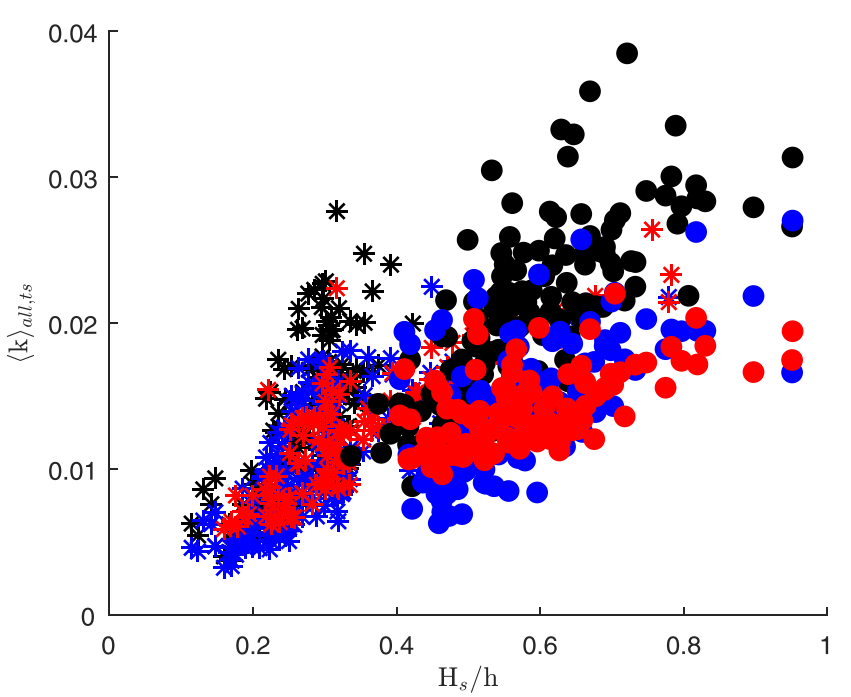

Figure 8. Froude-scaled TKE $\left(k_{\text {all,ts }}\right)$ versus relative wave height $\left(H_{S} / h\right)$. Data from Durras beach are represented by circles, and data from Vejers beach are shown by asterisks. Near-bed measurements, ADV1 (lower sensor), are presented in red, ADV2 (middle sensor) in blue, and ADV3 (upper sensor) in black. positions. Note, however, that the thresholds between different breaker types were not validated for Vejers beach since video data were unavailable.

\subsection{Short-Wave Suspended Sediment Flux and Flux Efficiency Under Swell and Wind Wave Conditions}

Given the dominant swell conditions $(T)$ and coarser sand grain sizes (and thereby $w_{s}$ ) at Durras beach, $q_{s, h f}$ was expected to be onshore-directed and larger than at Vejers beach and the flux efficiency was also expected to be larger. The combined effect of wave period and sediment grain size on $q_{s, h f}$ is examined (i.e., short-wave periods and fine sand versus long-wave periods and medium sand) because the amount of data available with similar wave periods but for different sediment grain sizes was insufficient to determine the effect of sediment grain size in isolation. Near-bed $(z<$ $0.10 \mathrm{~m}) q_{s, h f_{H_{z} / h_{z}}}$ at the two beaches is shown in Figure 12a. For breaking waves with $H_{z} / h_{z}>0.4, q_{s, h f} H_{z} / h_{z}$ was onshore-directed (i.e., positive) at both beaches, but significantly larger at Durras beach, as expected. $C_{H_{z} / h_{z}}$ was also significantly larger at Durras beach for similar $H_{z} / h_{z}$ (Figure 12b), which is at least partly the reason for the larger $q_{s, h f_{H_{z}} / h_{z}}$. Near-bed turbulence has previously been shown to be an important 


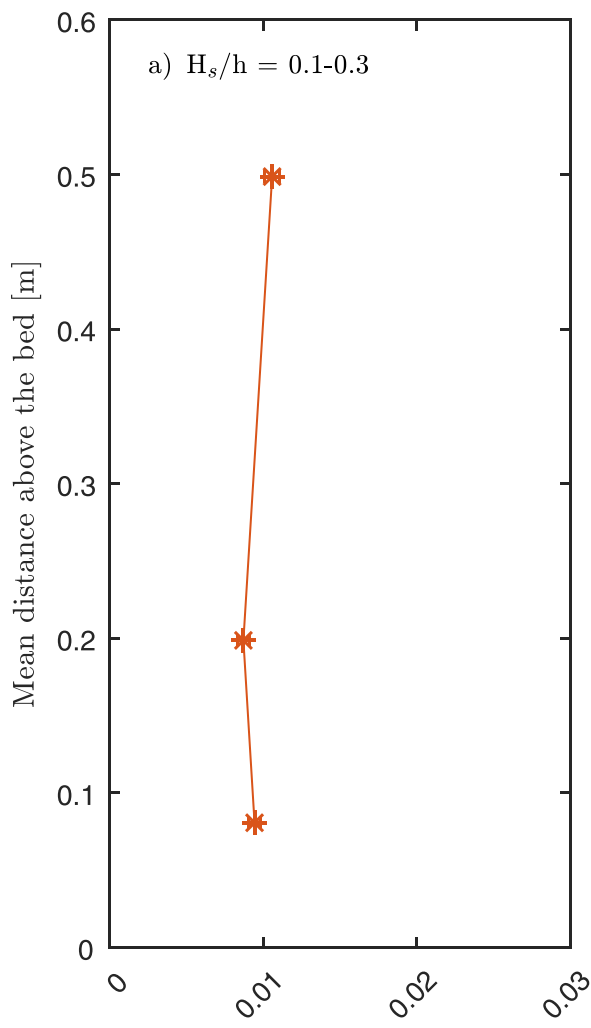

$\langle\mathrm{k}\rangle_{H_{s} / h}$

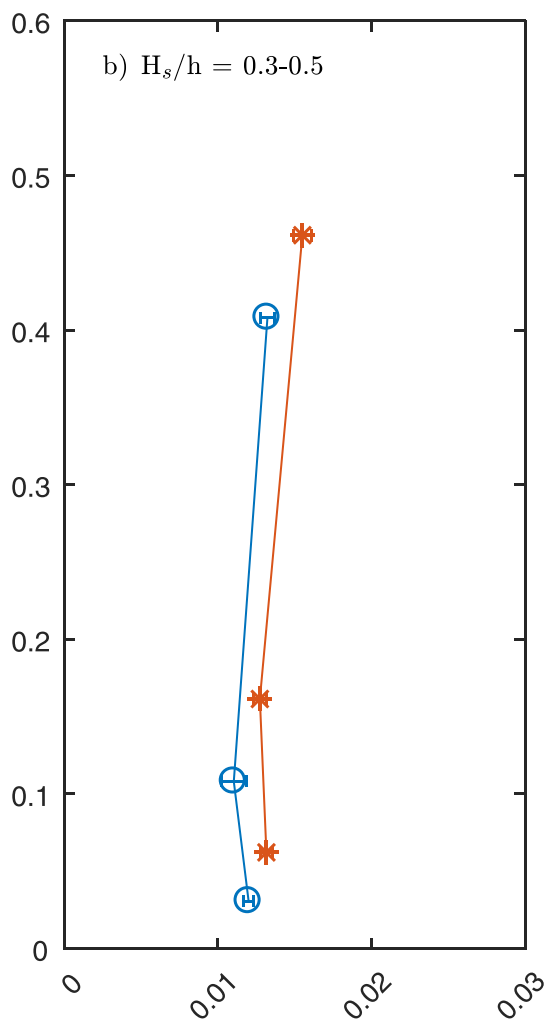

$\langle\mathrm{k}\rangle_{H_{s} / h}$

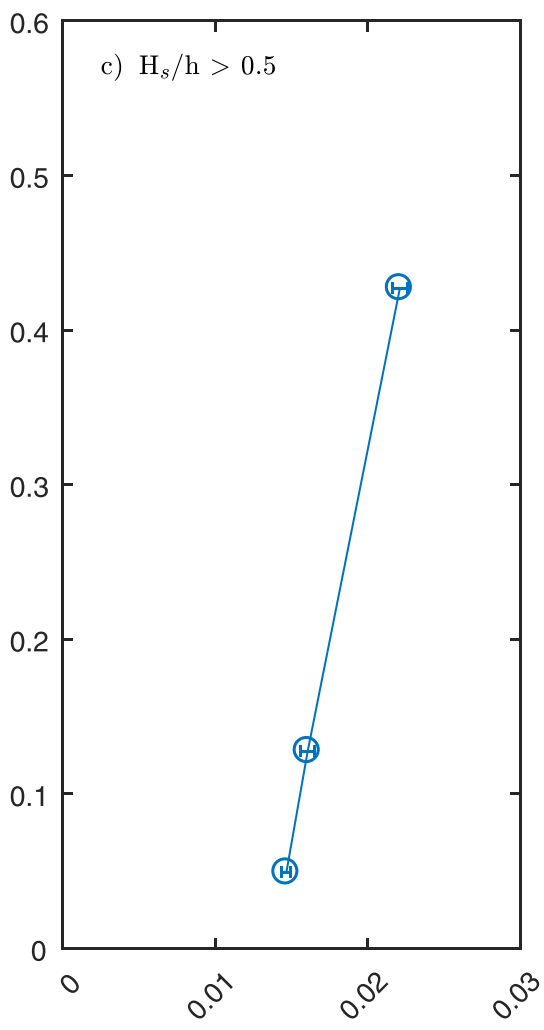

$\langle\mathrm{k}\rangle_{H_{s} / h}$

Figure 9. Vertical structure of Froude-scaled $T K E\left(k_{H_{s} / h}\right)$ for three relative wave height-bins: (a) $H_{S} / h=0.1-0.3$, (b) $H_{S} / h=0.3-0.5$, and (c) $H_{S} / h>0.5$. Data from Durras beach are represented by blue circles and data from Vejers beach by orange asterisks. The horizontal lines show the standard error on the means.
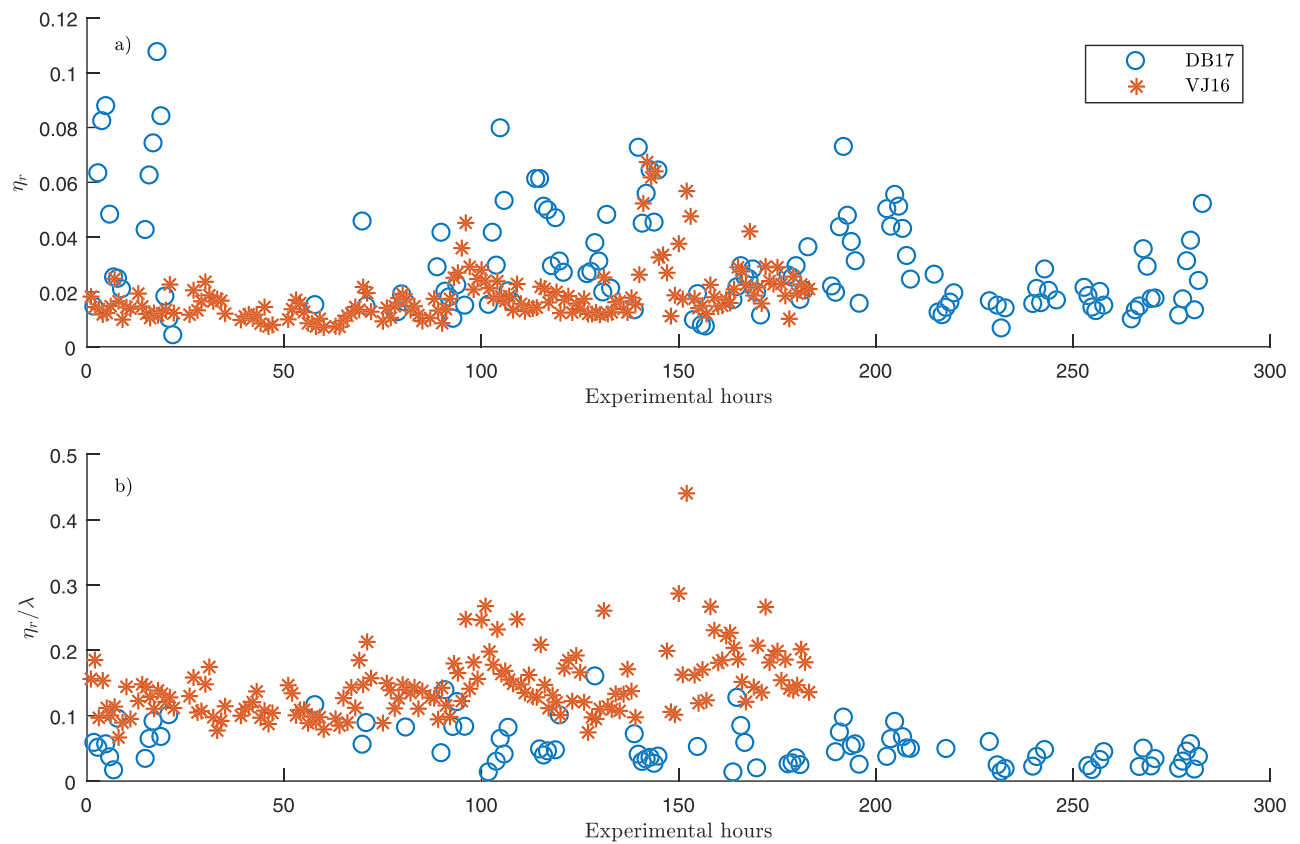

Figure 10. (a) Bed form height $\left(\eta_{r}\right)$ and (b) steepness $\left(\eta_{r} / \lambda\right)$ at the location of the instrument rigs. Data from Durras beach are represented by blue circles and data from Vejers beach by orange asterisks. 


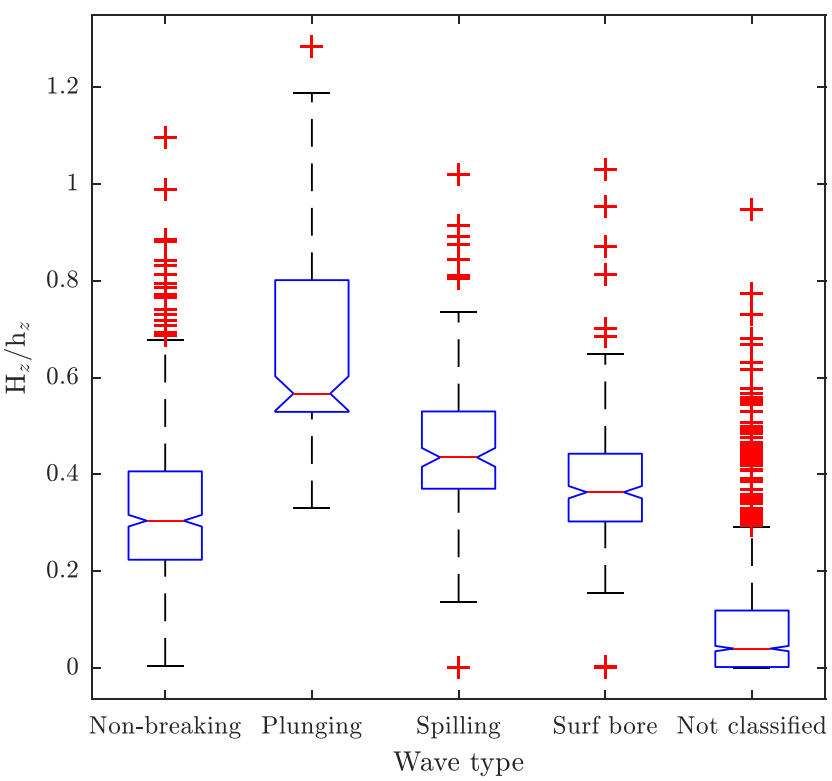

Figure 11. Box plot of visually classified waves (nonbreaking, plunging breakers, spilling breakers, surf bores, and not classified). In each box the central, the red mark indicates the median relative wave height of the waves, the notch is the $95 \%$ confidence interval on the median, and the top and bottom edges of the boxes indicate the 75th and 25th percentiles. The whiskers show the extent of the most extreme data points (data points within $\pm 2.7 \sigma$ ). Outliers not covered by the extent of the whiskers are represented by red crosses. driver for sediment suspension (e.g., Aagaard et al., 2018; Christensen et al., 2019; van der Zanden et al., 2017), and therefore, higher turbulence intensities were expected at Durras beach in order to suspend more sediment despite the larger grain sizes compared to Vejers beach (Figure 3). However, $k_{\text {mean, }} \mathrm{ADV}_{H_{z}} / h_{z}$ was not systematically significantly different at the two beaches for similar $H_{z} / h_{z}$ (Figure 12c). Maximum intrawave $k$ ( $k_{\mathrm{ADV} 1, \max _{H_{z} / h_{z}}}$ within individual wave cycles) was, on the other hand, significantly larger at Durras beach compared to Vejers beach (Figure 12d), which indicates a larger temporal variability of turbulence injection (within a wave cycle) at Durras beach. This is supported by larger standard deviations of $k_{\mathrm{ADV} 1}$ at Durras beach (Figure 13). The results suggest that it is the maximum turbulence intensity within a wave cycle that defines how much sediment is brought into suspension, which is in agreement with previous studies on intrawave variability of turbulence and suspended sediment concentrations (e.g., Aagaard \& Hughes, 2010; Brinkkemper, de Bakker, et al., 2017; Christensen et al., 2019). So, the higher $k_{\mathrm{ADV} 1, \max _{H_{z} / h_{z}}}$ at Durras beach may explain the larger $C_{H_{z} / h_{z}}$ and thus $q_{s, h f_{H_{z} / h_{z}}}$. In addition, measurements might more frequently have been obtained within the wave boundary layer at Durras beach compared to Vejers beach as the boundary layer thickness is expected to be higher. This could also contribute to the higher $C_{H_{z} / h_{z}}$ at Durras beach.

Contrary to expectations, flux efficiency (eliminating variability in $q_{s, h f_{H_{z} / h_{z}}}$ caused by, for example, different sensor elevations) was not significantly different at the two beaches (Figure 14). For breaking waves
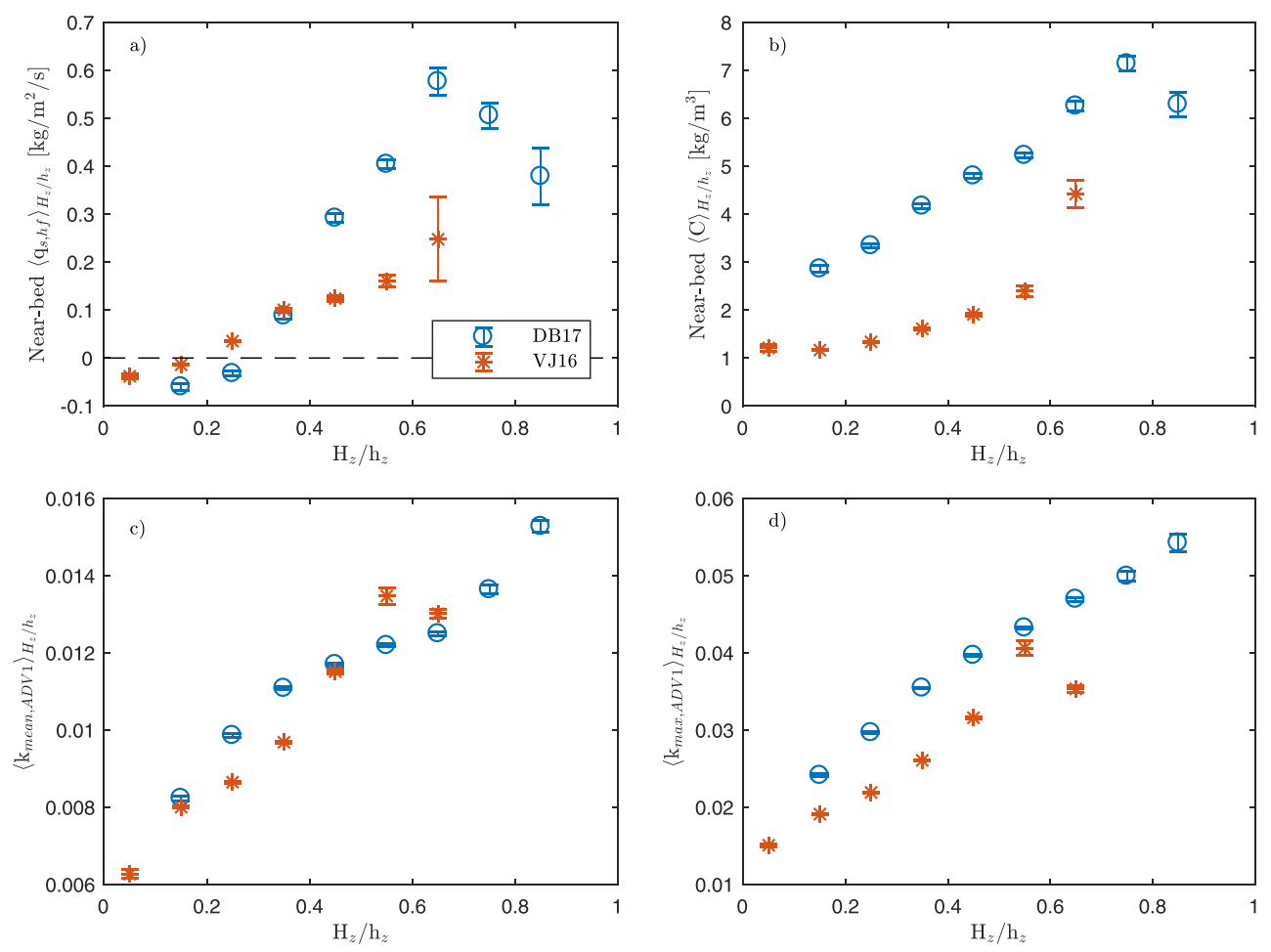

Figure 12. *a) Near-bed $(z<0.10 \mathrm{~m})$ wave-averaged short-wave suspended sediment flux $\left(q_{s, h f_{H_{z} / h_{z}}}\right)$, (b) near-bed $(z<0.10)$ wave-averaged suspended sediment concentration $\left(C_{H_{z} / h_{z}}\right)$, (c) wave-cycle-averaged Froude-scaled TKE ( $\left.k_{\text {mean, ADV1 }} H_{z} / h_{z}\right)$, and (d) maximum Froude-scaled TKE within a wave cycle $\left(k_{\max , A D V} H_{z} / h_{z}\right)$, all plotted as a function of relative wave height $\left(H_{z} / h_{z}\right)$. Data from Durras beach are represented by blue circles and data from Vejers beach by orange asterisks. The error bars show the standard error on the means. 


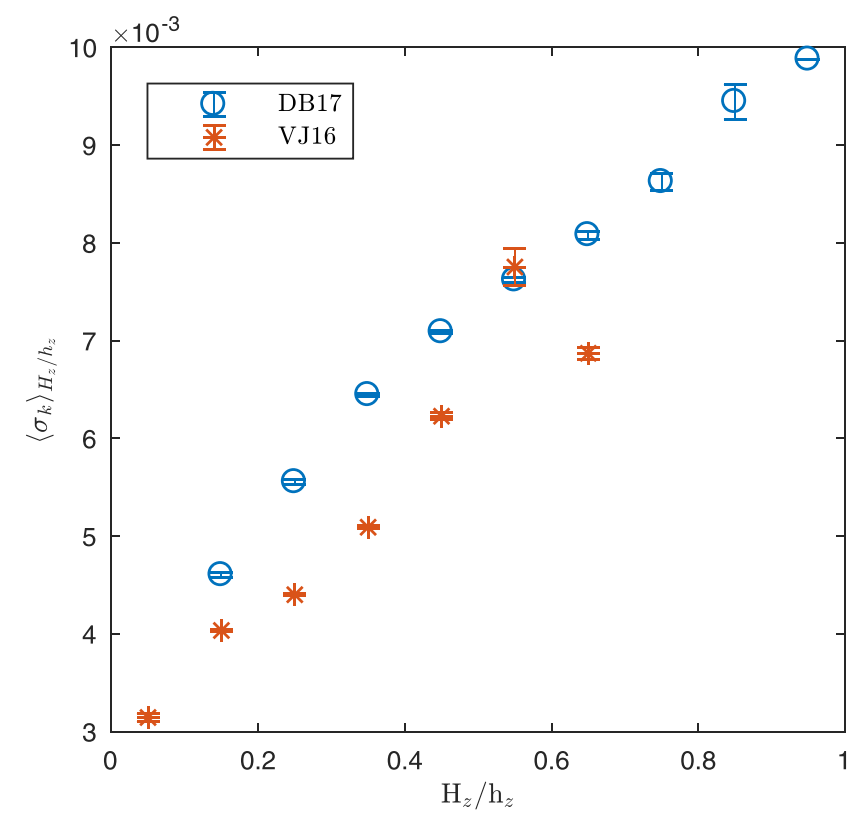

Figure 13. The mean standard deviation of Froude-scaled $T K E\left(\sigma_{k H_{z} / h_{z}}\right)$ versus relative wave height $\left(H_{z} / h_{z}\right)$. Data from Durras beach are represented by blue circles and data from Vejers beach by orange asterisks. The error bars show the standard error on the means.
( $\left.H_{z} / h_{z}>0.3\right), q_{s, h f} / C_{H_{z} / h_{z}}$ was generally of comparable magnitude at the two beaches, and even perhaps with a slight tendency toward larger $q_{s, h f} / C_{H_{z} / h_{z}}$ at Vejers beach. Hence, for similar relative wave heights, the longer wave periods and coarser grain sizes at Durras beach compared to Vejers beach did not contribute to smaller phase-lag effects and hence larger onshore, short-wave suspended sediment fluxes.

The flux efficiency did, however, increase in magnitude with an increase in $H_{z} / h_{z}$ (up to $H_{z} / h_{z}=0.6-0.7$ ). This might have been related to the expected increase in velocity asymmetry of the waves with an increase in $H_{z} / h_{z}$. Velocity asymmetry is suggested to cause suspension skewness by increasing the bed shear stress on the wave crest phase (e.g., Nielsen, 1992; Foster, Bowen, et al., 2006) and thereby contribute to increasing the short-wave suspended sediment flux. However, $H_{z} / h_{z}$ is also associated with different wave types (section 3.2), which suggests that $q_{s, h f} / C_{H_{z} / h_{z}}$ is related to wave breaker type due to different magnitudes and intrawave variations in turbulence intensity and thus suspended sediment concentrations. It has so far been difficult to distinguish between the effects of velocity asymmetry and turbulence for suspension skewness (e.g., Brinkkemper et al., 2018; Christensen et al., 2019).

Plunging breakers $\left(H_{z} / h_{z}>0.5\right)$, which are typically associated with longperiod swell waves and relatively steep (coarse-grained) beaches (Battjes, 1974), were more efficient in transporting suspended sediment onshore than spilling breakers and surf bores $\left(H_{z} / h_{z}=0.3-0.5\right)$. For nonbreaking waves ( $\left.H_{z} / h_{z}<0.3\right), q_{s, h f} / C_{H_{z} / h_{z}}$ was small or offshore-directed (e.g., negative) at both beaches (Figure 14). These variations in flux efficiencies with wave type imply that the flux efficiency increases from the shoaling (nonbreaking) wave zone to the outer surf zone (plunging and spilling breakers) and then decreases into the inner surf zone where surf bores dominate.

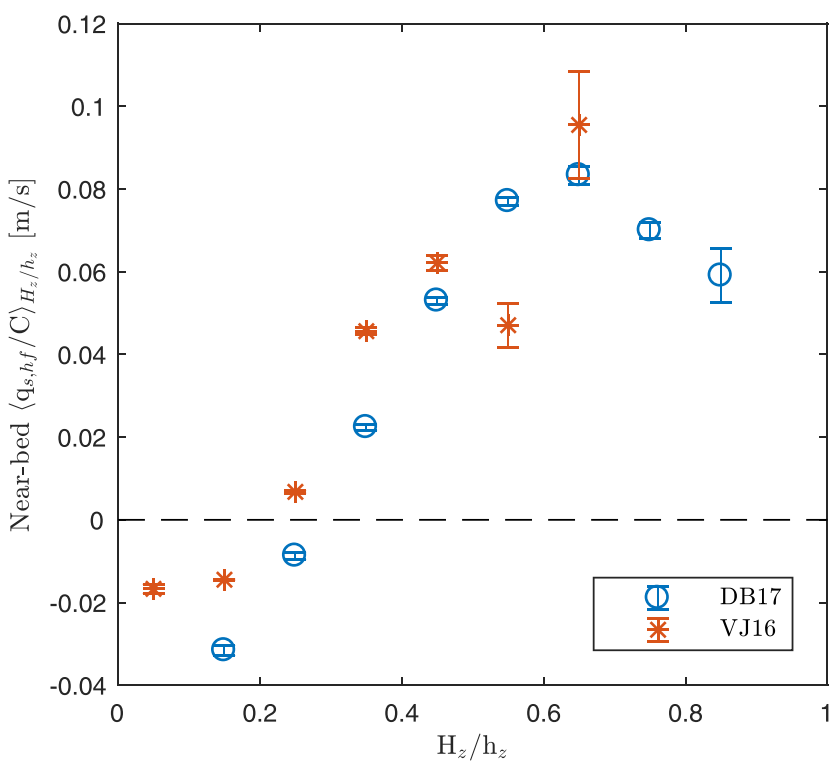

Figure 14. Near-bed $(z<0.10 \mathrm{~m})$ flux efficiency $\left(q_{s, h f} / C_{H_{z / h}}\right)$ versus relative wave height $\left(H_{z} / h_{z}\right)$. Data from Durras beach are represented by blue circles and data from Vejers beach by orange asterisks. The error bars show the standard error on the means.
At Vejers beach, the offshore-directed transport beneath nonbreaking waves was likely related to vortex shedding from bed forms. Christensen et al. (2019) examined the intrawave variability in the suspended sediment concentration during the TASTI field experiment and showed that the suspension of sediment beneath the trough phase of the shoaling waves was related to cases with steep wave ripples $\left(\eta_{r} / \lambda>0.12\right)$. This indicated that vortex shedding occurred, even though the wave ripples were formally classified as being of the postvortex type. At Durras beach, the wave ripples were of lower steepness (Figure 10b) and vortex shedding is therefore less likely to have occurred. Instead, an examination of waves with $H_{z} / h_{z}<0.3$ at Durras beach revealed that a large fraction of these relatively small waves occurred on the back of a preceding breaking wave and therefore typically displayed a negative mean velocity (Figure 15). Examination of the video records showed that such secondary waves were often caused by deshoaling and release of higher harmonics (Masselink, 1998) when the primary wave propagated across the trough landward of the inner nearshore bar. The negative mean velocity of the waves can explain the negative flux efficiency for this class of waves.

\subsection{The Influence of Infragravity Waves and Undertow on $q_{s, h f}$}

Even though the data support the hypothesis that plunging breakers are more efficient than spilling breakers and surf bores in transporting suspended sediment onshore (on account of their larger ratios of $H_{z} / h_{z}$ ), large standard deviations within each $H_{z} / h_{z}$-bin (Table 4) imply that flux 


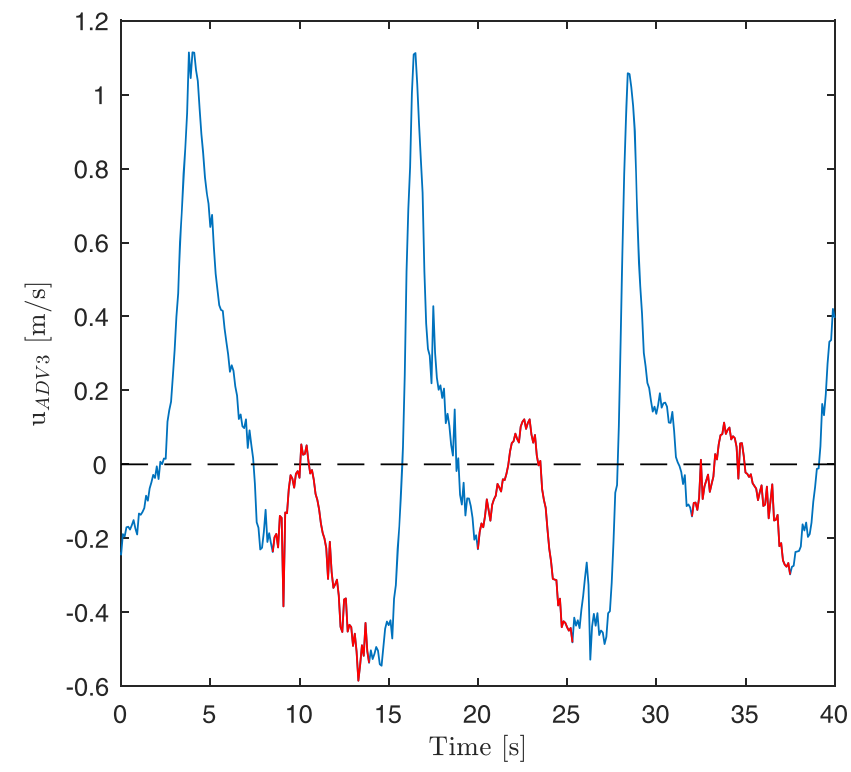

Figure 15. A subset of a velocity time series $\left(u_{\mathrm{ADV} 3}\right)$ from Durras beach showing three waves with $H_{z} / h_{z}<0.2$ highlighted in red (at time stamps 8-12 s, 20-25 s, and 32-37 s) all located on the back of a preceding breaking wave $\left(H_{z} / h_{z}>0.3\right)$.

efficiency cannot be unambiguously related to relative wave height, and additional factors must affect $q_{s, h f}$. Two time series recorded at Durras beach were selected in order to examine potential causes of the different flux efficiencies for the same $H_{z} / h_{z}$. The two cases have comparable $H_{S} /$ $h, A S_{u, \mathrm{ADV} 3}$, and $T_{s}$ but significantly different $q_{s, h f} / C_{\text {all,ts }}$ (Table 5).

Time series of $u_{\mathrm{ADV} 3}, T K E$, and near-bed $c$ (at $z=0.05 \mathrm{~m}$ ) for the two cases are shown in Figure 16. In addition, phase-averages of $u_{\mathrm{ADV} 3}$ and $c$ are shown in Figure 17. Comparing the time series, there is a distinct difference in the suspension patterns with much more regular suspension events for run 140 (Figure 16) and more rapid sediment settling (Figure 17). No phase-lag between $u$ and $c$ thus existed in run 140 (Figure 17a), and the flux efficiency was consequently large. The opposite was the case for run 254 (Figure 17b). Events of suspended sediment concentrations in run 140 were in most cases related to events of high TKE beneath the largest waves (Figure 16). Visual observations in the field showed that the largest waves were plunging at the instrument rig, and the high level of TKE in the upper part of the water column $\left(k_{\mathrm{ADV} 3}\right.$; Table 5) also indicates a high degree of breaking-induced turbulence. This probably penetrated to the bed and suspended sediment as TKE events appear to be connected to the passing of the wave fronts and not the wave crests. In run 254, peaks in TKE and $c$ were smaller and less regular, indicating that the key driver of sediment suspension differed from run 140. The larger turbulence intensity near the bed $\left(k_{\mathrm{ADV} 1}\right.$; Table 5$)$ than higher in the water column ( $k_{\mathrm{ADV} 3}$; Table 5$)$ indicates that sediment suspension was significantly affected by bed-generated turbulence. Mean cross-shore current velocities that can affect boundary layer processes were significantly stronger during run 254 compared to run 140 (Table 5). The stronger undertow, despite similar wave conditions at the position of the instrument rig, was probably a result of undertow processes already being initiated offshore of the instrument rig during run 254. A primary plunging breakpoint was observed at an offshore located bar; waves were reforming and then plunging again near the instruments. By contrast, the primary breakpoint was located near the instrument rig during run 140. In addition to undertow velocities, infragravity waves were also more energetic during run 254 (Table 5). Accordingly, wave-current interactions and long-/short-wave interactions are likely to have affected the bed shear stress and thereby sediment suspension during run 254.

In order to examine more generally to which extent undertow and infragravity waves contributed to decreasing the flux efficiencies for breaking waves at Durras and Vejers beaches, near-bed flux efficiencies for waves with $H_{z} / h_{z}=0.4-0.5$ are related to infragravity wave-energy and cross-shore current speed in Figure 18 . The relative wave height-bin, $H_{z} / h_{z}=0.4-0.5$, was chosen as a reasonable example for all cases of breaking waves $\left(H_{z} / h_{z}>0.3\right)$. It is clear that time series containing significant amounts of infragravity wave-energy $\left(>5 \mathrm{~m}^{2} /\right.$ $\mathrm{s}^{2}$; Figure 18a) and relatively strong undertow $(<-0.1 \mathrm{~m} / \mathrm{s}$; Figure $18 \mathrm{~b})$ were associated with small flux efficiencies. This suggests that long-/short-wave interactions and wave-current interactions complicate the phase-relationship between $u$ and $c$ and cause a decrease in $q_{s, h f}$.

Reverting to our analysis of flux efficiencies at the two beaches (Figure 14), and now excluding time series with $S_{\eta}(f<0.05)>5 \mathrm{~m}^{2} / \mathrm{s}^{3}$ and $U<-0.1 \mathrm{~m} / \mathrm{s}, q_{s, h f} / C_{H_{z} / h_{z}}$ is significantly larger at Durras than at Vejers when the short waves are breaking $\left(H_{z} / h_{z}>0.3\right.$; Figure 19). Consequently, it may be inferred that when the phase-relationship between $u$ and $c$ is not complicated by long/short-wave interactions and wave-current

Table 4

The Flux Efficiencies $\left(q_{s, h f} / C_{H_{7} / h_{7}}\right)$ and Their Standard Deviations (in Parentheses) for Different Relative Wave Height Bins

\begin{tabular}{|c|c|c|c|c|c|c|c|c|c|}
\hline Sites & $H_{z} / h_{z}=0-0.1$ & $H_{z} / h_{z}=0.1-0.2$ & $H_{z} / h_{z}=0.2-0.3$ & $H_{z} / h_{z}=0.3-0.4$ & $H_{z} / h_{z}=0.4-0.5$ & $H_{z} / h_{z}=0.5-0.6$ & $H_{z} / h_{z}=0.6-0.7$ & $H_{z} / h_{z}=0.7-0.8$ & $H_{z} / h_{z}=0.8-0.9$ \\
\hline DB17 & & $-0.03( \pm 0.04)$ & $-0.01( \pm 0.05)$ & $0.02( \pm 0.06)$ & $0.05( \pm 0.06)$ & $0.08( \pm 0.07)$ & $0.08( \pm 0.09)$ & $0.07( \pm 0.05)$ & $0.06( \pm 0.07)$ \\
\hline VJ16 & $-0.02( \pm 0.02)$ & $-0.01( \pm 0.02)$ & $0.01( \pm 0.04)$ & $0.05( \pm 0.08)$ & $0.06( \pm 0.10)$ & $0.05( \pm 0.09)$ & $0.10( \pm 0.07)$ & & \\
\hline
\end{tabular}


Table 5

Flux Efficiency $\left(q_{s, h f} / C_{\text {all,tss }}\right)$, Significant Wave Height $\left(H_{s}\right)$, Relative Wave Height $\left(H_{s} / h\right)$, Significant Wave Period $\left(T_{S}\right)$, Velocity Asymmetry $\left(A S_{u}\right.$, ADV3), Froude-Scaled TKE (k), Mean Cross-Shore Current Velocity $\left(U_{A D V 3}\right)$, and Infragravity Wave Energy $\left(S_{\eta}(f<0.05 \mathrm{~Hz})\right)$ of the Time Series, Run 140 and Run 254

\begin{tabular}{lll}
\hline Parameters & Run 140 & Run 254 \\
\hline$\left.q_{s, h f} / C_{\text {all, ts }}\right)(\mathrm{m} / \mathrm{s})$ & 0.39 & 0.03 \\
$H_{S}(\mathrm{~m})$ & 0.51 & 0.55 \\
$H_{S} / h$ & 0.58 & 0.57 \\
$T_{S}(\mathrm{~s})$ & 4.6 & 4.4 \\
$A S_{u, \mathrm{ADV} 3}$ & -0.72 & -0.66 \\
$k_{\mathrm{ADV} 3}$ & 0.015 & 0.013 \\
$k_{\mathrm{ADV} 1}(\mathrm{~m} / \mathrm{s})$ & 0.011 & 0.015 \\
$U_{\mathrm{ADV} 3}$ & -0.06 & -0.20 \\
$S_{\eta}(f<0.05 \mathrm{~Hz})\left(\mathrm{m}^{2} / \mathrm{s}^{2}\right)$ & 2.4 & 4.5 \\
\hline
\end{tabular}

occasionally deshoaling and release of higher harmonics resulted in mean positive (negative) velocities for waves of large (small) $H_{z} / h_{z}$. This may have caused some overestimates of onshore-directed $q_{s, h H_{H_{z}} / h_{z}}$ for a small fraction of the waves with $H_{z} / h_{z}>0.3$.

The larger $q_{s, h f_{H_{z} / h_{z}}}$ at Durras beach was a result of larger $C_{H_{z} / h_{z}}$ in spite of coarser bed sediment. Interestingly, $k_{H_{z} / h_{z}}$, which contributes to increase the bed shear stress and sediment mobilization (e.g., Nielsen, 1992; van Rijn et al., 2013), was not larger at Durras beach compared to Vejers beach, for a given $H_{z} / h_{z}$-bin. Maximum $k$ within the wave cycle was, on the other hand, significantly larger at Durras beach
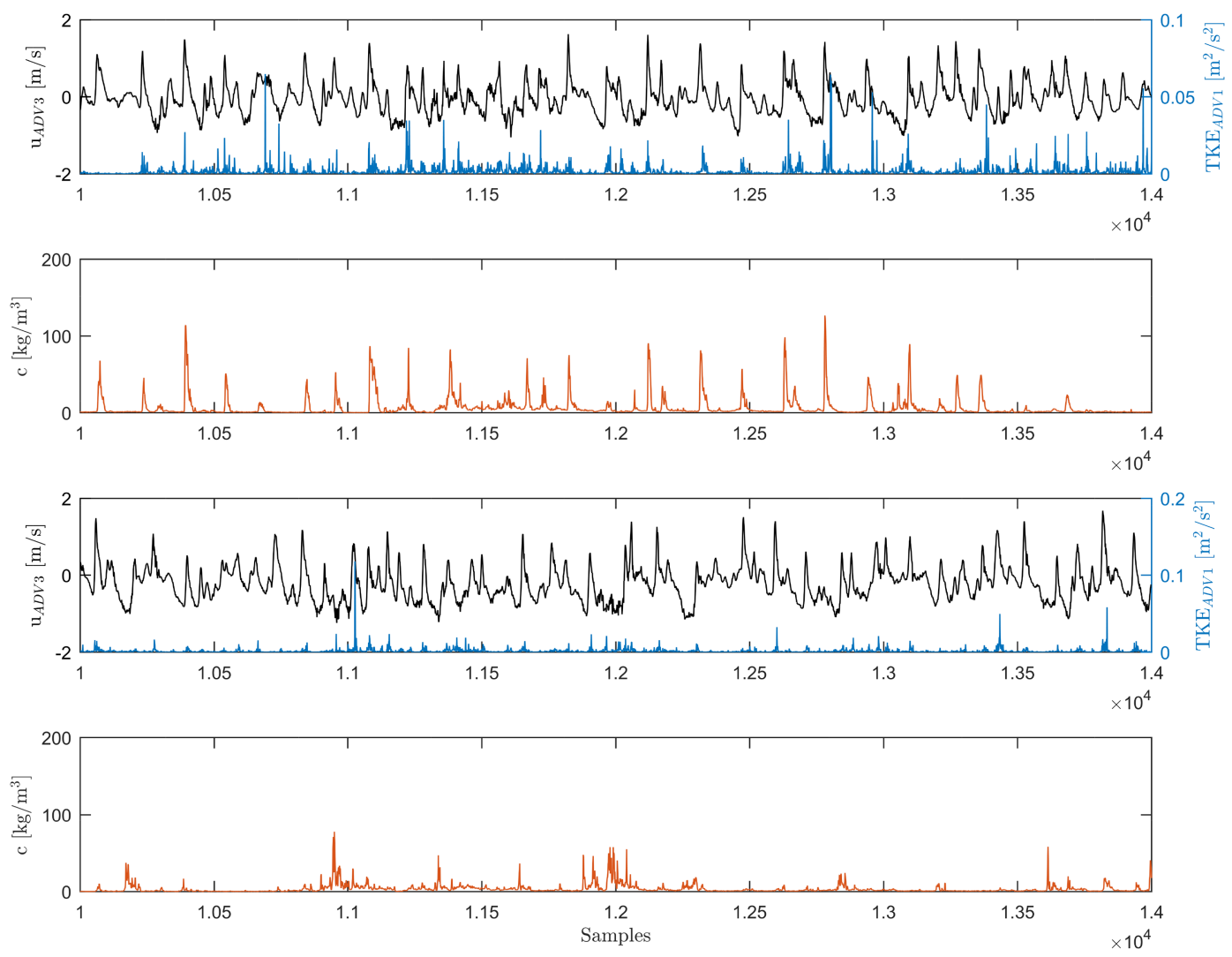

Figure 16. Time series subset (approximately $7 \mathrm{~min}$ ) of (a and c) cross-shore orbital velocity $\left(u_{\mathrm{ADV} 3}\right)$ and turbulent kinetic energy (TKE $\left.\mathrm{ADV} 1\right)$ and (b and d) suspended sediment concentration $(c)$ at $z=0.05 \mathrm{~m}$ for ( $\mathrm{a}$ and $\mathrm{b}$ ) run 140 and ( $\mathrm{c}$ and d) run 254. Both time series were measured at Durras beach. 

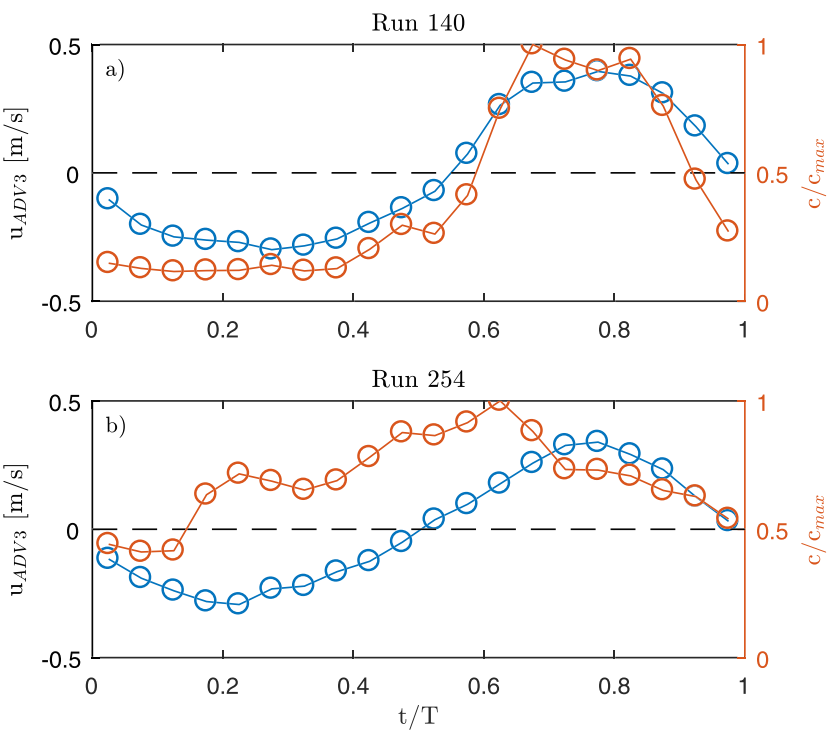

Figure 17. Phase-averaged cross-shore velocity, $u_{\mathrm{ADV} 3}(t / T)$ and normalized suspended sediment concentration, $c(t / T)$, with respect to $c_{\max }(t / T)$ for (a) run 140 and (b) run 254. (for a given $H_{z} / h_{z}$ ). Hence, $k_{\max H_{z} / h_{z}}$ is suggested to be critical for sediment suspension in order to explain the larger $C_{H_{z} / h_{z}}$ at Durras beach. This is consistent with a study by Aagaard et al. (2018), which showed a stronger correlation between wave-phase-dependent $k(t)$ and $c(t)$ compared to wave-averaged values. The larger $\sigma_{k H_{z} / h_{z}}$ at Durras beach compared to Vejers beach indicates stronger intrawave variability in $k$, which can, at least partly, be related to the longer wave periods at Durras beach (Figure 5), because turbulence is more likely to dissipate prior to a new production event when the wave period is long. In addition, waves were more frequently breaking as plunging breakers at Durras beach ( section 3.2), and Ting (2002) showed that beneath plunging breakers, turbulence generally dissipates within one wave cycle resulting in larger temporal variations in TKE compared to spilling breakers.

In order to eliminate errors associated with different instrument elevations on the short-wave suspended sediment flux, $q_{s, h f_{H_{z} / h_{z}}}$ was scaled by $C_{H_{z} / h_{z}}$. The scaling moreover contributes to highlighting the importance of intrawave variations in $c$ for $q_{s, h f}$, since dissimilarities associated with different sediment suspension efficiencies are also eliminated. Intrawave variations in $c$ are, however, related to instrument elevation in cases of small vertical mixing. As the maximum elevation difference between used (F)OBSs in this study was $0.07 \mathrm{~m}$ and the vertical mixing generally was large, variations in sensor elevations are not expected to affect the flux efficiencies significantly. The standard deviations on the flux efficiencies within each $H_{z} / h_{z}$-bin can, nevertheless, partly be due to sensor elevation differences between time series.
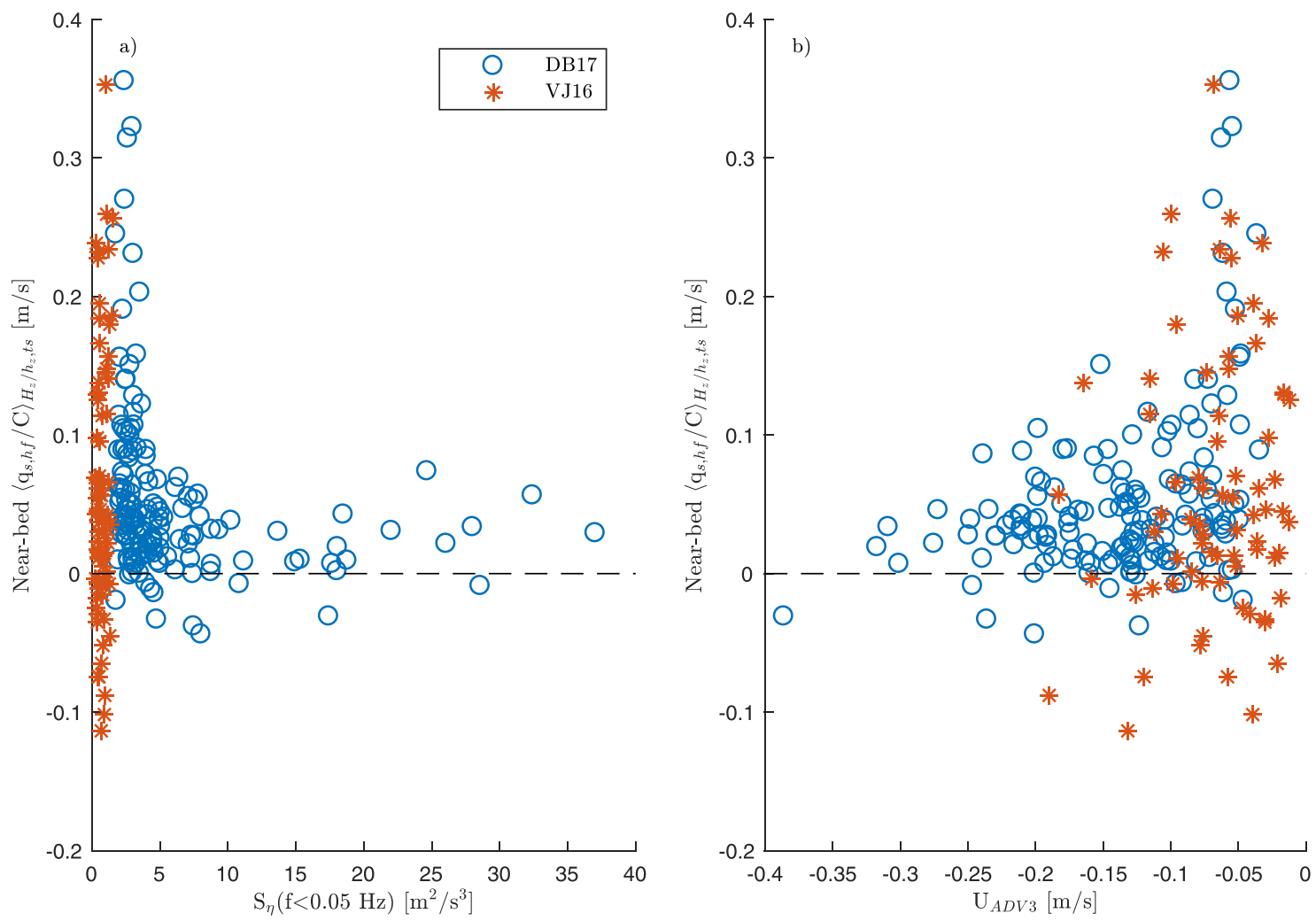

Figure 18. Near-bed $(z<0.10 \mathrm{~m})$ flux efficiency $\left(q_{s, h f} / C_{H_{z}}\right)$ for waves with $H_{z} / h_{z}=0.4-0.5$ versus $(\mathrm{a})$ infragravity wave energy $\left(S_{\eta}(\mathrm{f}<0.05 \mathrm{~Hz})\right)$ and $(\mathrm{b})$ cross-shore mean current velocity $\left(U_{\mathrm{ADV} 3}\right)$. Data from Durras beach are represented by blue circles and data from Vejers beach by orange asterisks. 


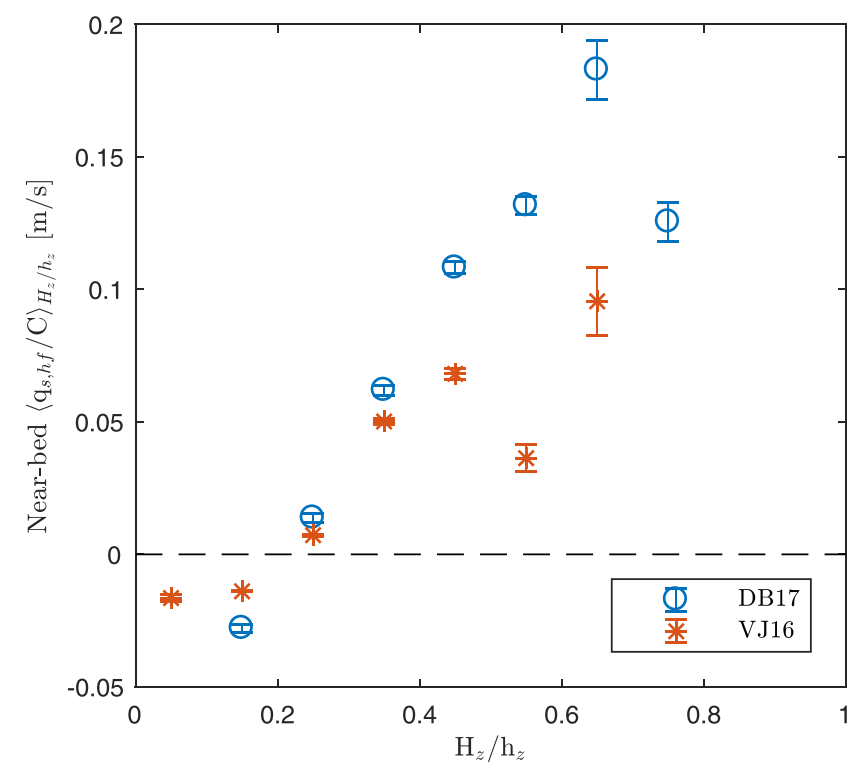

Figure 19. Near-bed $(z<0.10 \mathrm{~m})$ flux efficiency $\left(q_{s, h f} / C_{H_{z}}\right)$ versus relative wave height $\left(H_{z} / h_{z}\right)$. Only time series with $S_{\eta}(f<0.05) \stackrel{H_{z} / \mathrm{h}_{z}}{5^{2}} \mathrm{~m}^{2} / \mathrm{s}^{3}$ and $U>$ $-0.1 \mathrm{~m} / \mathrm{s}$ are included in the analysis. Data from Durras beach are represented by blue circles and data from Vejers beach by orange asterisks. The error bars show the standard error on the means.
Contrary to expectations, the scaling resulted in $q_{s, h f} / C_{H_{z} / h_{z}}$ of nearsimilar magnitude at the two beaches: based on $\Omega$, the longer wave periods and coarser sediment at Durras beach would have been expected to cause smaller phase-lags and consequently larger flux efficiencies than at Vejers beach. However, long-/short-wave interactions and wavecurrent interactions at Durras beach were shown to reduce temporal variation in $c$ despite the longer wave periods (and coarser sediment) and cause a degradation of $q_{s, h f} / C_{H_{z} / h_{z}}$. Strong undertow has earlier been shown to result in a lack of correlation between $c$ and $k$, possibly as a result of sediment advection by the mean current (Scott et al., 2009; Yoon \& Cox, 2012). When advection of sediment is significant, sediment concentration and flux efficiency are not exclusively determined by local sediment pick-up processes. This causes temporally inconsistent sediment suspension patterns and reduces intrawave variations in $c$, whereby $q_{s, h f}$ decreases. Similarly, infragravity waves have previously been shown to cause advection of suspended sediment (Aagaard \& Greenwood, 2008). A further complication is the increased bed shear stress on the wave trough phase caused by strong undertow, which increases $c$ on the wave trough phase and thereby reduces onshore-directed $q_{s, h f}$, or results in a reversal (Ruessink et al., 2011).

Thus, in order to study potential effects of wave period on flux efficiencies, it would seem that additional insight is obtained by excluding time series containing strong cross-shore mean currents and infragravity waveenergies. Considering only time series with weak infragravity energy $\left(S_{\eta}(f<0.05)<5 \mathrm{~m}^{2} / \mathrm{s}^{3}\right)$ and weak cross-shore current speed $(U>-0.1 \mathrm{~m} / \mathrm{s})$ resulted in larger flux efficiencies beneath breaking waves $\left(H_{Z}\right)$ $\left.h_{z}>0.3\right)$ at Durras beach compared to Vejers beach. Swell wave conditions were thus more efficient in transporting suspended sediment onshore than wind waves when infragravity waves and/or undertow were absent. This is likely a result of smaller phase-lag effects as modeled by Ruessink et al. (2009) and predicted by $\Omega$. However, not only the effects of wave period and sand grain size are critical. The present experiments also suggested the wave (breaker) type to be important through the relationship with $H_{z} / h_{z}$, since the wave (breaker) type affects the $u / c$-phase-relationship and therefore $q_{s, h}$. At Durras beach, plunging breakers $\left(H_{z} /\right.$ $h_{z}>0.5$ ) were common (an estimated $32 \%$ of the waves passing the instrument position were in the process of plunging), while spilling breakers prevailed at Vejers beach (2\% plunging breakers at the instruments). Intrawave variations in TKE and $c$ are largest beneath plunging breakers where coherent breaker-vortices penetrate toward the bed slightly ahead of or on the front phase of the wave (Aagaard \& Hughes, 2010; Aagaard et al., 2018; Brinkkemper, de Bakker, et al., 2017). Beneath spilling breakers, diffusive mixing dominates, and the slower penetration of breaking-induced turbulence toward the bed typically result in sediment suspension on the back slope of the waves (Aagaard et al., 2018; Brinkkemper, de Bakker, et al., 2017; Christensen et al., 2019). In addition, this study showed that plunging breakers suspended larger amounts of sediment possibly due to larger $k_{\max }$ within the wave cycle, and thereby resulted in larger onshore-directed $q_{s, h f_{H_{z} / h_{z}}}$. To summarize, beach recovery during low/moderate-energy swell wave conditions may be a result of both smaller phase-lag effects as hypothesized by $\Omega$ (longer $T$ and larger $D$ ) and the dominance of plunging breakers. Plunging breakers are more efficient in onshore transport compared to spilling breakers and surf bores, because (i) sediment is suspended earlier on the wave phase and (ii) undertow and offshore infragravity transport are typically smaller than beneath surf bores in the inner surf zone.

\section{Conclusions}

The efficiency of wind and swell waves in transporting suspended sediment onshore, and thereby contributing to beach recovery, was examined based on data collected in the surf zones of Vejers beach, Denmark, and Durras beach, Australia. On Vejers beach, wind waves dominated and the sediment was fine grained with a mean size of $188 \mu \mathrm{m}$, while at Durras beach swell waves dominated and the sediment was coarser $(360 \mu \mathrm{m})$. 
Despite the different wave and sediment conditions, the flux efficiency for breaking waves at the two beaches was found to be within the same order of magnitude. However, excluding time series with strong infragravity wave energy $\left(S_{\eta}(f<0.05)>5 \mathrm{~m}^{2} / \mathrm{s}^{3}\right)$ and undertow velocities $(U<-0.1 \mathrm{~m} / \mathrm{s})$ significantly increased the flux efficiencies at Durras beach, especially. This resulted in flux efficiencies that were larger beneath breaking waves at Durras beach compared to Vejers beach. So swell wave periods favored onshore-directed $q_{s, h f}$ as expected (based on $\Omega$ ) but only in cases when the $u / c$-phase-relationship was not degraded by infragravity wave interaction and strong undertow. The importance of wave period for $q_{s, h f}$ can be related to both phase-lag effects (i.e., sediment is more likely to settle before flow reversal if the wave period is long) but also wave breaker type. Swell wave conditions are typically associated with plunging breakers, while spilling breakers often prevail during wind-wave conditions (Battjes, 1974). Examination of $q_{s, h f} / C_{H_{z} / h_{z}}$ for different $H_{z} / h_{z}$ showed that plunging breakers $\left(H_{z} / h_{z}>0.5\right)$ were more efficient than spilling breakers/surf bores $\left(H_{z} /\right.$ $\left.h_{z}=0.3-0.5\right)$ and nonbreaking waves $\left(H_{z} / h_{z}<0.3\right)$ in transporting suspended sediment onshore. In addition, plunging breakers suspended larger concentrations of sediment, which resulted in larger $q_{s, h f} H_{z} / h_{z}$. The results indicate that wave period and breaker type are essential factors to incorporate in a parameterisation of $q_{s, h f}$ but also that more factors such as long/short-wave interactions and wave-current interactions are of significance.

\section{Acknowledgments}

The present work was funded by The Danish Council for Independent Research (grant 4181-00045),

University of Copenhagen. The depth, velocity, and sediment concentration data are available from UCPH ERDA (http://www.doi.org/10.17894/ ucph.51d7ef85-1b1f-43e2-9ab183025c749ea5). We would like to thank Mathias Madsen, Per Freiberg, and Paul Christiansen for their assistance during the field campaigns.

\section{References}

Aagaard, T., \& Greenwood, B. (2008). Infragravity wave contribution to surf zone sediment transport - The role of advection. Marine Geology, 251, 1-14. https://doi.org/10.1016/j.margeo.2008.01.017

Aagaard, T., \& Hughes, M. (2013). Sediment transport. In J. F. Shroder (Ed.), Treatise on Geomorphology (Vol. 10, pp. 74-105). San Diego: Academic Press.

Aagaard, T., Hughes, M., Møller-Sørensen, R., \& Andersen, S. (2006). Hydrodynamics and sediment fluxes across an onshore migrating intertidal bar. Journal of Coastal Research, 222, 247-259. https://doi.org/10.2112/04-0214.1

Aagaard, T., \& Hughes, M. G. (2010). Breaker turbulence and sediment suspension in the surf zone. Marine Geology, 271, 250-259.

Aagaard, T., Hughes, M. G., \& Ruessink, G. (2018). Field observations of turbulence, sand suspension, and cross-shore transport under spilling and plunging breakers. Journal of Geophysical Research: Earth Surface, 123, 2488-2862. https://doi.org/10.1029/2018JF004636 Aagaard, T., \& Jensen, S. G. (2013). Sediment concentration and vertical mixing under breaking waves. Marine Geology, 336, 146-159.

Aagaard, T., Kroon, A., Greenwood, B., \& Hughes, M. G. (2010). Observations of offshore bar decay: Sediment budgets and the role of lower shoreface processes. Continental Shelf Research, 30, 1497-1510. https://doi.org/10.1016/j.csr.2010.05.010

Aagaard, T., \& Masselink, G. (1999). The surf zone. In A. D. Short (Ed.), Handbook of beach and shoreface morphodynamics (pp. 72-118). Chichester: John Wiley \& Sons.

Aubrey, D. G., Inman, D. L., \& Winant, C. D. (1980). The statistical prediction of beach changes in Southern California. Journal of Geophysical Research, 85(C6), 3264-3276.

Bailard, J. A. (1981). An energetics total load sediment transport model for a plane sloping bed. Journal of Geophysical Research, 86, $10,938-10,954$

Battjes, J. A. (1974). Computation of set-up, longshore currents, run-up and overtopping due to wind-generated waves. Delft University of Technology, PhD-dissertation.

Bertin, X., de Bakker, A., van Dongeren, A., Coco, G., André, G., Ardhuin, F., et al. (2018). Infragravity waves: From driving mechanisms to impacts. Earth-Science Reviews, 177, 774-799. https://doi.org/10.1016/j.earscirev.2018.01.002

Brinkkemper, J. A., Aagaard, T., de Bakker, A. T. M., \& Ruessink, B. G. (2018). Shortwave sand transport in the shallow surf zone. Journal of Geophysical Research: Earth Surface, 123, 1145-1159. https://doi.org/10.1029/2017JF004425

Brinkkemper, J. A., Christensen, D. F., Price, T., Naus, I., Hansen, A., van Bergeijk, V., et al. (2017). Surf zone morphodynamics during lowmoderate energetic conditions; the TASTI field experiment. Proceedings Coastal Dynamics, 2017, 1038-1048.

Brinkkemper, J. A., de Bakker, A. T. M., \& Ruessink, B. G. (2017). Intrawave sand suspension in the shoaling and surf zone of a field-scale laboratory beach. Journal of Geophysical Research: Earth Surface, 122, 356-370. https://doi.org/10.1002/2016JF004061

Bruun, P. (1954). Coastal erosion and the development of beach profiles. Beach Erosion Board Technical Memo 44.

Chappell, J., \& Eliot, I. G. (1979). Surf-beach dynamics in time and space-An Australian case study, and elements of predictive model. Marine Geology, 32, 231-250.

Christensen, D. F., Brinkkemper, J. A., Ruessink, B. G., \& Aagaard, T. (2018). Field observations of turbulence in the intertidal and shallow subtidal zones. Continental Shelf Research, 170, 21-32. https://doi.org/10.1016/j.csr.2018.10.002

Christensen, D. F., Brinkkemper, J. A., Ruessink, B. G., \& Aagaard, T. (2019). Field observations of intra-wave sediment suspension and transport in the intertidal and shallow subtidal zones. Marine Geology, 413, 10-26. https://doi.org/10.1016/j.margeo.2019.04.005

Davidson, M. A., \& Turner, I. L. (2009). A behavioral template beach profile model for predicting seasonal to interannual shoreline evolution. Journal of Geophysical Research, 114, F01020. https://doi.org/10.1029/2007JF000888

Dean, R. G. (1973). Heuristic models of sand transport in the surf zone. In First Australian Conference on Coastal Engineering: Engineering Dynamics of the Coastal Zone. Sydney, NSW: Institution of Engineers, Australia.

Dubois, R. N. (1988). Seasonal changes in beach topography and beach volume in Delaware. Marine Geology, 81, 79-96.

Elgar, S., Raubenheimer, B., \& Guza, R. T. (2005). Quality control of acoustic Doppler velocimeter data in the surf zone. Measurement Science and Technology, 16, 1889-1893.

Emery, W. J., \& Thomson, R. E. (2001). Data analysis methods in physical oceanography (second ed. p. 638). Amsterdam: Elsevier.

Foster, D. L., Beach, R. A., \& Holman, R. A. (2006). Turbulence observations of the nearshore wave bottom boundary layer. Journal of Geophysical Research, 111, C04011. https://doi.org/10.1029/2004JC002838 
Foster, D. L., Bowen, A. J., Holman, R. A., \& Natoo, P. (2006). Field evidence of pressure gradient induced incipient motion. Journal of Geophysical Research, 111, C05004. https://doi.org/10.1029/2004JC002863

Gallagher, E. L., Elgar, S., \& Guza, R. T. (1998). Observations of sand bar evolution on a natural beach. Journal of Geophysical Research, 103(C2), 3203-3215.

Galvin, C. J. (1968). Breaker type classification on three laboratory beaches. Journal of Geophysical Research, 73(12), 3651-3659.

Gourlay, M. . (1968). Beaches: Profiles, processes and permeability. In Proceedings of the $17^{\text {th }}$ Coastal Engineering Conference, American Society of Civil Engineers (Vol. 2, pp. 1320-1339).

Hay, A. E. (2011). Geometric bed roughness and the bed state storm cycle. Journal of Geophysical Research, 116, C04017. https://doi.org/ 10.1029/2010JC006687

Henderson, S. M., Allen, J. S., \& Newberger, P. A. (2004). Nearshore sandbar migration predicted by an eddy-diffusive boundary layer model. Journal of Geophysical Research, 109, C06024. https://doi.org/10.1029/2003JC002137

Kobayashi, N., \& Jung, H. (2012). Beach erosion and recovery. Journal of Waterway, Port, Coastal, and Ocean engineering, ASCE. https:// doi.org/10.1061/(ASCE)WW.1943-5460.0000147

Lord, D., \& Kulmar, M. (2000). The 1974 storms revisited: 25 years experience in ocean wave measurements along the south-east Australian coastline. Proceedings $27^{\text {th }}$ International Conference on Coastal Engineering, ASCE, Sydney, 559-572.

Mariño-Tapia, I. J., O'Hare, T. J., Russell, P. E., Davidson, M. A., \& Huntley, D. A. (2007). Cross-shore sediment transport on natural beaches and its relation to sandbar migration patterns: 2. Application of the field transport parameterization. Journal of Geophysical Research, 112, CO3002. https://doi.org/10.1029/2005JC002894

Masselink, G. (1998). Field investigation of wave propagation over a bar and the consequent generation of secondary waves. Coastal Engineering, 33, 1-9.

Miller, J. K., \& Dean, R. G. (2004). A simple new shoreline change model. Coastal Engineering, 51, 531-556. https://doi.org/10.1016/j. coastaleng.2004.05.006

Mocke, G. B. (2001). Structure and modelling of surf zone turbulence due to wave breaking. Journal of Geophysical Research, 106, 17,039-17,057.

Mori, N., Suzuki, T., \& Kakuno, S. (2007). Noise of acoustic Doppler velocimeter data in bubbly flows. Journal of Engineering Mechanics, $133,122-125$.

Morton, R. A., Pain, J. G., \& Gibeaut, J. C. (1994). Stages and durations of post-storm beach recovery, Southeastern Texas Coast, U.S.A. Journal of Coastal Research, 10(4), 884-908.

Nielsen, P. (1992). Coastal bottom boundary layers and sediment transport (p. 324). Singapore: Advanced Series on Ocean Engineering World Scientific.

Osborne, P. D., \& Greenwood, B. (1992). Frequency dependent cross-shore suspended sediment transport. 2. A barred shoreface. Marine Geology, 106, 25-51.

Philips, M. S., Harley, M. D., Turner, I. L., Splinter, K. D., \& Cox, R. J. (2017). Shoreline recovery on wave-dominated sandy coastlines: The role of sandbar morphodynamics and nearshore wave parameters. Marine Geology, 385, 146-159.

Ruessink, B. G. (2010). Observation of turbulence within a natural surf zone. Journal of Physical Oceanography, 40, $2696-2712$.

Ruessink, B. G., \& Kuriyama, Y. (2008). Numerical predictability experiments of cross-shore sandbar migration. Geophysical Research Letters, 35, L01603. https://doi.org/10.1029/2007GL032530

Ruessink, B. G., Michallet, H., Abreu, T., Sancho, F., Van der A, D. A., van der Werf, J. J., \& Silva, P. A. (2011). Observations of velocities, sand concentrations, and fluxes under velocity-asymmetric oscillatory flows. Journal of Geophysical Research, 116, C03004. https://doi. org/10.1029/2010JC006443

Ruessink, B. G., van den Berg, T. J. J., \& van Rijn, L. C. (2009). Modeling sediment transport beneath skewed asymmetric waves above a plane bed. Journal of Geophysical Research, 114, C11021. https://doi.org/10.1029/2009JC005416

Scott, C. P., Cox, D. T., Maddux, T. B., \& Long, J. W. (2005). Large-scale laboratory observations of turbulence on a fixed barred beach. Measurement Science and Technology, 16, 1903-1912.

Scott, N. V., Hsu, T.-J., \& Cox, D. (2009). Steep wave, turbulence, and sediment concentration statistics beneath a breaking wave field and their implications for sediment transport. Continental Shelf Research, 29, 2303-2317. https://doi.org/10.1016/j.csr.2009.09.008

Shepard, F. P. (1950). Beach cycles in Southern California. US Army Corps of Engineers, Beach Erosion Board, Tech, Memo 20.

Short, A. D. (2007). Beaches of the New South Wales Coast: A guide to their nature, characteristics, surf and safety (2nd ed.). Sydney, New South Wales, Australia: Sydney University Press.

Soulsby, R. (1997). Dynamics of marine sands: A manual for practical applications. London: Thomas Telford.

Splinter, K. D., Holman, R. A., \& Plant, N. G. (2011). A behavior-oriented dynamic model for sandbar migration and 2DH evolution. Journal of Geophysical Research, 116, C01020. https://doi.org/10.1029/2010JC006382

Thornton, E. B., Humiston, R. T., \& Birkemeier, W. (1996). Bar/trough generation on a natural beach. Journal of Geophysical Research, 101, $12,097-12,110$.

Ting, F. C. K. (2002). Laboratory study of wave and turbulence characteristics in narrow-band irregular breaking waves. Coastal Engineering, 46, 291-313.

van der Werf, J. J., Doucette, J. S., O'Donoghue, T., \& Ribberink, J. S. (2007). Detailed measurements of velocities and suspended sand concentrations over full-scale ripples in regular oscillatory flow. Journal of Geophysical Research, 112, F02012. https://doi.org/10.1029/ 2006JF000614

van der Zanden, J., van der A, D. A., Hurther, D., Cáceres, I., O'Donoghue, T., \& Ribberink, J. S. (2017). Suspended sediment transport around a large-scale laboratory breaker bar. Coastal Engineering, 125, 51-69. https://doi.org/10.1016/j.coastaleng.2017.03.007

van Rijn, L. C., Ribberink, J. S., van der Werf, J., \& Walstra, D. J. R. (2013). Coastal sediment dynamics: recent advances and future research needs. Journal of Hydraulic Research, 51(5), 475-493. https://doi.org/10.1080/00221686.2013.849297

Wright, L. D., \& Short, A. D. (1984). Morphodynamic variability of surf zones and beaches: a synthesis. Marine Geology, 56, 93-118.

Wright, L. D., Short, A. D., \& Green, M. O. (1985). Short-term changes in the morphodynamic states of beaches and surf zones: An empirical predictive model. Marine Geology, 62, 339-364.

Yates, M. L., Guza, R. T., O'Reilly, W. C., Hansen, J. E., \& Barnard, P. L. (2011). Equilibrium shoreline response of a high wave energy beach. Journal of Geophysical Research, 116, C04014. https://doi.org/10.1029/2010JC006681

Yoon, H.-D., \& Cox, D. T. (2012). Cross-shore variation of intermittent sediment suspension and turbulence induced by depth-limited wave breaking. Continental Shelf Research, 47, 93-106. https://doi.org/10.1016/j.csr.2012.07.001 